\title{
NAC1 Modulates Autoimmunity by Suppressing Regulatory T Cell- Mediated Tolerance
}

Jin-Ming Yang1,\#, Yijie Ren, *, Anil Kumar, , ${ }^{2}$ Xiaofang Xiong², Jugal Kishore Das ${ }^{2}$, Hao-Yun Peng $^{2}$, Liqing Wang ${ }^{2}$, Xingcong Ren ${ }^{1}$, Yi Zhang ${ }^{1}$, Cheng Ji ${ }^{1}$, Yan Cheng ${ }^{1}$, Li Zhang ${ }^{1}$, Robert C. Alaniz $^{2}$, Paul de Figueiredo ${ }^{2,3}$, Deyu Fang ${ }^{4}$, Xiaoqi Liu' ${ }^{1}$, Jianlong Wang 5 , Jianxun Song 2 ,\#

${ }^{1}$ Department of Toxicology and Cancer Biology, Department of Pharmacology and Nutritional Science, and Markey Cancer Center, University of Kentucky College of Medicine, Lexington, KY 40536, USA

${ }^{2}$ Department of Microbial Pathogenesis and Immunology, Texas A\&M University Health Science Center, Bryan, TX 77807, USA

${ }^{3}$ Department of Veterinary Pathobiology, Texas A\&M University; Norman Borlaug Center, Texas A\&M University, College Station, TX 77845, USA

${ }^{4}$ Department of Pathology, Northwestern University Feinberg School of Medicine, Chicago, IL 60611, USA

${ }^{5}$ Department of Medicine, Columbia Center for Human Development, Columbia University Irving Medical Center, New York, NY 10032, USA

* These authors contributed equally to this work

${ }^{\#}$ Correspondence to: Jin-Ming Yang or Jianxun Song

1095 V.A. Drive, 306 Health Science Research Building, Lexington, KY 40536-0305. Tel: +1 859 562 2154; Fax: +1 859257 6030; E-mail: jyang@uky.edu

MREB II, Room 3344, 8447 Riverside Pkwy, Bryan, TX 77807. Tel: +1 979436 0633; Fax: +1 979436 0991; E-mail: jus35@tamu.edu 


\begin{abstract}
$\mathrm{FoxP}^{+}$regulatory $\mathrm{T}$ cells (Tregs) are a distinct subset of $\mathrm{CD}^{+} \mathrm{T}$ cells integral to the maintenance of the balance of the immune system, and their dysregulation is a trigger of autoimmunity. We report here that nucleus accumbens-associated protein-1 (NAC1), a nuclear factor of the broad complex, tramtrack, bric-a-brac / poxvirus and zinc finger (BTB/POZ) gene family, is a negative regulator of FoxP3 in Tregs and a critical determinant of immune tolerance. Phenotypically, $\mathrm{NAC1}^{-/-}$mice show substantial tolerance to the induction of autoimmunity, as evidenced by the significantly decreased occurrences of autoimmune arthritis and colitis. Analysis of $\mathrm{T}$ cells from the wild-type (WT) or NAC1 knockout $\left(^{-/-}\right)$mice found that NAC1 is crucially involved in the early stage of $\mathrm{T}$ cell development. NAC1 positively affects $\mathrm{CD}^{+} \mathrm{T}$ cell differentiation, but negatively regulates Treg development. Compared with WT animals, $\mathrm{NAC1}^{-/}$ mice displayed defects in $\mathrm{CD}^{+} \mathrm{T}$ cell development but generated a larger amount of $\mathrm{CD}^{+}$ regulatory Tregs that exhibit a higher metabolic profile and immune suppressive activity, increased acetylation, and expression of FoxP3, and slower turnover of this transcriptional factor. Furthermore, treatment of Tregs with the pro-inflammatory cytokines IL-1 $\beta$ or TNF- $\alpha$ induced a robust upregulation of NAC1 but an evident downregulation of FoxP3 as well as the acetylated FoxP3, suggesting that the reduction of FoxP3 by the NAC1-mediated deacetylation and destabilization of this lineage-specific transcriptional factor contributes considerably to break of immune tolerance. These findings imply that the pro-inflammatory cytokines-stimulated upregulation of NAC1 acts as a trigger of the immune response through destabilization of Tregs and suppression of tolerance induction, and that therapeutic targeting of NAC1 warrants further exploration as a potential tolerogenic strategy for treatment of autoimmune disorders.
\end{abstract}




\section{Introduction}

Aberrant autoimmunity results in over 80 different autoimmune diseases that are often debilitating and life-threatening, for which there is no cure at present. Autoimmune diseases such as Crohn's disease, type-1 diabetes mellitus (T1D), rheumatoid arthritis (RA) and ulcerative colitis (UC) are believed to result from interaction between genetic and environmental factors and to be a consequence of compromised immune tolerance versus adaptive immune response. Immune tolerance prevents an immune response to a particular antigen (Ag) or tissues that cause autoimmune disorders, and a range of immune cell types participate in the control of hyposensitivity of the adaptive immune system to the self-Ag or non-self-Ag.

Among these immune cells, FoxP ${ }^{+}$regulatory $\mathrm{T}$ cells (Tregs), a distinct and dynamic subset of $\mathrm{CD}^{+} \mathrm{T}$ cells, are an essential contributor to the immune tolerance, maintenance of immune cell homeostasis and the balance of the immune system; and defects in Tregs occur in virtually all the autoimmune disorders (1). The stability of the suppressor Tregs is critical for their function but is reduced in most of the autoimmune disorders. Therefore, maintenance of the Treg stability is crucial for immunologic tolerance. Yet, how impaired balance between immune response and tolerance is triggered and the key molecular determinants that affect Treg stability remain elusive.

Here, we report our new finding that nucleus accumbens-associated protein-1 (NAC1), encoded by NACCl gene and originally identified as a cocaine-inducible transcript from the nucleus accumbens (2), acts as a vital modulator of immune suppression. NAC1 is a nuclear factor that belongs to the BTB (Broad-Complex, Tramtrack and Bric a brac)/POZ (POX virus and Zinc

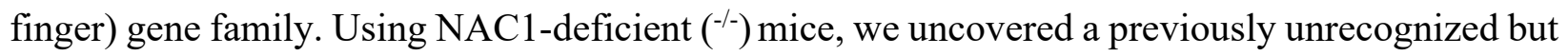
important role of NAC1 in triggering autoimmunity and Treg instability and demonstrated that 
bioRxiv preprint doi: https://doi.org/10.1101/2022.03.01.482525; this version posted March 4, 2022. The copyright holder for this preprint (which was not certified by peer review) is the author/funder. All rights reserved. No reuse allowed without permission.

NAC1 contributes to break of immune tolerance through its negative control of Treg development and function associated with deacetylation and destabilization of FoxP3 protein. 


\section{Results}

\section{Overall $\mathrm{T}$ cell population is divergent in the $\mathrm{WT}$ and $\mathrm{NAC1}^{-/-}$mice}

Previous studies have shown that NAC1 participates in regulation of the self-renewal and pluripotency of embryonic stem cells (3-5) and somatic cell reprogramming (6), and we recently found that NAC1 has a critical role in cellular metabolism (7). As metabolic reprogramming can significantly influence $\mathrm{T}$ cell activation, expansion, and effector function $(8,9)$, we queried whether NAC1 affects T cell development and function. We first performed T cell profiling in WT and $\mathrm{NACl}^{-/-}$mice. Compared with WT mice, development of $\mathrm{T}$ cells in the thymus of $\mathrm{NAC1}^{-/-}$ mice was curbed, as evidenced by increased numbers of thymocytes in the dominant-negative (DN) stage (1.67\% vs. $0.72 \%)$ and decreased numbers of cells in the DN4 stage $(4.65 \%$ vs. $28.5 \%$; $p<0.0001$ ) (Fig. 1A). Although $\mathrm{NAC1}^{-/-}$mice showed a reduction of total thymocytes and decreased cell amount in the DN4 stage, an accumulation of T cells in the DN2 stage was observed in those animals (49.1.5\% vs. 28.7\%; $<<0.0001)$ (Fig. 1A, Fig. 1B). These alterations were correlated with a decreased percentage of TCR $\beta^{+}$cells in DN4 cells found in $\mathrm{NAC} 1^{-/-}$mice. Despite a higher $\%$ of DN cells in $\mathrm{NAC1}^{-/-}$mice, which show higher numbers of CD1 $17^{+}$cells, WT animals had a greater number of $\mathrm{TCR} \beta^{+}$cells than $\mathrm{NAC1} 1^{-/-}$mice. Like the gating on the $\mathrm{DN} 4$ population, there was a decrease in $\mathrm{TCR} \beta^{+}$cells in $\mathrm{NAC1}^{-/-}$mice as compared with WT animals, which could be due to a higher \% of DN4 cells in WT mice (Extended Fig. 1). Conversely, in the lymph nodes (LNs) and spleen of $\mathrm{NACl}^{-/-}$mice, there was a reduced percentage of $\mathrm{CD}^{+} \mathrm{T}$ cells $(28.5 \% v s$. $40.5 \%)$ but an increased percentage of $\mathrm{CD}^{+} \mathrm{T}$ cells $(66.3 \%$ vs. $57.3 \%)$ as compared to the controls (Fig. 1C). Despite the similar numbers of the total $\mathrm{CD}^{+}$or $\mathrm{CD}^{+}$single positive (SP) $\mathrm{T}$ cells in the thymus (Fig. 1B; lower panel), there were significant increases of $\%$ and numbers of CD4 ${ }^{+} \mathrm{SP}$ T cells $(p<0.05$ or $p<0.01)$ but a decrease of $\mathrm{CD}^{+}$SP T cells $(p<0.05$ or $p<0.01)$ in the pooled 
LNs and spleen in $\mathrm{NACl}^{-/-}$mice, as compared with WT controls (Fig. 1D; lower panel). These results suggest an important role for $\mathrm{NACl}$ in the early stage of $\mathrm{T}$ cell development and in the differentiation of $\mathrm{CD}^{+}$and $\mathrm{CD} 8^{+} \mathrm{SP}$ cells.

\section{Deficiency of NAC1 promotes Treg development and stability}

The significant increase of total peripheral $\mathrm{CD}^{+} \mathrm{T}$ cell population observed in $\mathrm{NAC1}^{-/-}$ mice (Fig. 1D) prompted us to ask whether NAC1 plays a regulatory role in the development of Tregs, a unique sub-type of $\mathrm{CD}^{+} \mathrm{T}$ cells able to suppress excessive immune reaction. Indeed, as compared with WT animals, $\mathrm{NAC1}^{-/-}$mice showed an evident increase in $\%$ of Tregs in the LNs, spleen and blood (Fig. 1E). Moreover, $\mathrm{NAC1}^{-/}$animals had significantly higher $\%$ and numbers of Tregs in the LNs and spleen but not in the thymus $(p<0.0001$; Fig. 1F). To prove the role of NAC1 in the development of Tregs, we used an in vitro system in which induced Tregs (iTregs) are generated from naive $\mathrm{CD} 4^{+} \mathrm{CD} 25^{-} \mathrm{T}$ cells $(10)$. The naive $\mathrm{CD} 4^{+} \mathrm{CD} 25^{-} \mathrm{T}$ cells from the $\mathrm{LNs}$ and spleen of WT or $\mathrm{NAC1}^{-/-}$mice were treated with TGF- $\beta$ to produce iTregs. The naive $\mathrm{CD}^{+}{ }^{+} \mathrm{CD} 25^{-} \mathrm{T}$ cells from WT mice expressed abundant NAC1 but no detectable FoxP3; notably, the iTregs from those $\mathrm{T}$ cells showed a robust expression of FoxP3 but a substantial reduction of NAC1 expression (Fig. 2A). Remarkably, a significantly greater amount of iTregs were generated from $\mathrm{NAC1}^{-/}$than from WT CD4 ${ }^{+} \mathrm{CD} 25^{-} \mathrm{T}$ cells (Fig. 2B-C). Furthermore, in response to stress, the expression of CD36, an immuno-metabolic receptor that mediates metabolic adaptation and supports Treg survival and function $(11,12)$, was significantly elevated in $\mathrm{NAC1}^{-/-}$Tregs as compared with WT Tregs (Fig. 2D-E). These results indicate that NAC1 exerts a negative control of Treg development at early stages. In addition to affecting $\mathrm{CD} 4^{+}$populations, $\mathrm{NAC} 1$ also affects $\mathrm{CD} 8^{+} \mathrm{T}$ cells. NAC1 deficiency led to a significant decrease of $\mathrm{CD}^{+} \mathrm{SP} \mathrm{T}$ cell generation in the 
LNs and spleen, reduced production of cytokine, and shortened cellular survival (Extended Fig. 2). Viral Ag-stimulated development of memory $\mathrm{CD}^{+} \mathrm{T}$ cells was also suppressed in the absence of NAC1 (Extended Fig. 3).

\section{$\mathrm{NAC1}^{-/-}$Tregs display enhanced functional activities}

To further validate the negative control of Treg development by NAC1, we examined the functional activity of the Tregs either from $\mathrm{WT}$ or $\mathrm{NAC1}^{-/-}$mice. $\mathrm{CD} 4^{+} \mathrm{CD} 25^{+}$Tregs from the $\mathrm{LNs}$ and spleen of WT or $\mathrm{NAC1}^{-/-}$mice were stimulated with the mouse CD3/CD28-loaded beads in the presence of rIL-2, and the metabolic differences between $\mathrm{WT}$ or $\mathrm{NAC1}^{-/}$cells were then analyzed using the Seahorse XF Cell Mito Stress Test kit. Although Tregs from WT or NAC1 ${ }^{-/}$ mice had similar proliferation and survival profiles (Fig. 3A-C), Tregs from $\mathrm{NAC1}^{-/}$mice exhibited a significantly higher oxygen consumption rate (OCR) and glycolytic rate (glycoPER) than Tregs from WT mice (Fig. 3D-E), suggesting that $\mathrm{NAC1}^{-/-}$Tregs are metabolically more active than the corresponding control Tregs. Consistently, $\mathrm{NAC1}^{-/}$Tregs produced significantly greater amounts of the suppressive cytokines, TGF- $\beta$ and IL-10, than WT Tregs, as shown by intracellular staining (Fig. 3F) and ELISA (Fig. 3G), which may constitute one of several mechanisms that contribute to the suppressive capacity of Tregs. These results clearly demonstrate a negative impact of NAC1 on the suppressive function of Tregs and imply that inhibiting NAC1 may modulate autoimmunity through promoting Treg development and function. The enhanced function of $\mathrm{NAC1}^{-/-}$Tregs was further demonstrated in an in vitro suppressive assay (Fig. 3H) and in an autoimmune colitis model subjected to in vivo co-transfer of Tregs with $\mathrm{CD}^{+} \mathrm{T}$ effectors (Teffs), which showed that $\mathrm{NAC1}^{-/-}$Tregs elicited a stronger immune suppressive effect on inflammation than WT Tregs. Transfer of naive Teffs into $\operatorname{Rag}^{-/-}$mice resulted in weight loss in 
two weeks, and co-transfer of Teffs with FoxP3 ${ }^{+}$Tregs (Treg/Teffs ratio of 1:3) from $\mathrm{NAC1}^{-/}$mice led to a significant reduction of weight loss compared with those of WT mice $(p<0.05$; Fig. 3I). The co-transfer of Teffs with $\mathrm{NAC1}^{-/}$and $\mathrm{WT} \mathrm{FoxP}^{+}$Tregs effectively protected from a decrease in finger-like villus projections (arrows) in the gut (Fig. 3J). Similarly, in the LPS-induced colitis, adoptive transfer of $\mathrm{NACl}^{-/-}$Tregs was more efficient in preventing colon loss than WT Tregs, as shown by the colon lengths (Fig. 3K-L), histology (an arrow indicates the goblet cell architecture of the colon tissue was damaged by LPS; Fig. 3M) and Treg infiltration in the draining LNs (Fig. 3N). Furthermore, we performed in vivo analyses on survival, proliferation/cell cycle, and apoptosis. WT and $\mathrm{NAC1}^{-/-}$Tregs $\left(\right.$Thy $\left.1.2^{+}\right)$were labeled with CFSE and i.v. injected into B6.Thy1.1 Tg mice. On Days 2 and 5 after Treg transfer, the pooled LNs and spleen were analyzed for the transferred Th1.2 $2^{+}$Tregs using flow cytometry. We found that $\mathrm{NACl}^{-/-}$Tregs had similar survival and proliferation/cell cycle (Fig. 30), but increased FoxP3 expression (Fig. 3P) and reduced apoptosis (Fig. 3Q) as compared with WT Tregs. In addition, we found that both NAC1/- iTregs and nTreg produced more suppressive cytokines (i.e., IL-10 and TGF- $\beta$ ) than WT cells, and the similarity between iTregs and nTregs (Extended Fig. 4). In a mouse tumor model receiving the in vivo co-transfer of Tregs with $\mathrm{CD}^{+} \mathrm{T}$ cells, $\mathrm{NAC1}^{-/}$Tregs displayed greater suppressive effect on antitumor immunity than the control Tregs (Extended Fig. 5), another evidence for the enhanced suppressive activity of $\mathrm{NAC1}^{-/-}$Tregs.

\section{$\mathrm{NAC1}^{-/-}$mice are insusceptible to induction of autoimmunity}

To further prove the impact of NAC1 on autoimmunity, next we compared the response of the WT and $\mathrm{NAC1}^{-/-}$mice to induction of autoimmune arthritis and colitis. Type II collagen was used to induce arthritis (13) and dextran sulfate sodium (DSS) was given to mice to induce colitis 
(14). We found that $\mathrm{NACl}^{-/-}$mice were significantly tolerant to induction of autoimmune arthritis and colitis (Fig. 4). In the collagen-induced arthritis model (CIA) (13), a significantly lower occurrence of CIA was observed in $\mathrm{NACl}^{-/-}$mice than in the littermate controls, as determined by the histologic evidence (Fig. 4A), disease incidence (Fig. 4B; $p<0.0001)$ and disease score (Fig. 4C; $p<0.0001)$. Tolerance to autoimmunity induction was recapitulated in a colitis model in which mice were given drinking water containing dextran sulfate sodium (DSS). WT mice developed autoimmune colitis within 3-4 days following DSS administration and showed visible signs of illness including hunched back, raised fur, symptoms of sepsis and reduced mobility because of diarrhea and anemia; strikingly, the occurrence of colitis declined remarkably in $\mathrm{NACl}^{-/-}$mice (Fig. 4D-H). In $\mathrm{NACl}^{-/-}$mice, the body weight loss (Fig. 4E), survival (Fig. 4F), colon shrinkage (Fig. 4G) and the disease activity index (Fig. 4H) were all significantly improved as compared with WT animals $(p<0.0001)$. In both of the disease models, there were considerably larger amounts of pro-inflammatory immune cells in the joint (Fig. 4A) and the colon (Fig. 4D) tissues of WT mice than in those of $\mathrm{NAC1}^{-/-}$animals (arrows), suggesting that weakened immune response may account for the insusceptibility of $\mathrm{NACl}^{-/-}$mice to induction of autoimmunity. As $\mathrm{NACl}^{-/-}$ mice showed enhanced numbers and functions of Tregs (Fig. 1, Fig. 3) and Tregs have a unique capacity to suppress immune response, the tolerance to the induction of autoimmune diseases observed in $\mathrm{NACl}^{-/-}$mice (Fig. 4) could be a consequence of the enhanced Treg stability.

\section{DNA methylation of FoxP3 in Tregs remains intact in the absence of NAC1}

Next, we sought to understand how NAC1 regulates the development and function of Tregs. As FoxP3 is a transcription factor essential for establishment and maintenance of Treg phenotype, and NAC1 may cooperate with certain transcriptional factors to regulate various 
cellular activity $(15,10)$, we therefore asked whether the effect of NAC1 on Tregs is mediated through its interaction with FoxP3.

Primarily, FoxP3 stability is associated with selective demethylation of an evolutionarily conserved element within the FoxP3 locus named TSDR (Treg-specific demethylated region) (17, 18). To determine whether the effect of NAC1 on Tregs is mediated through FoxP3 methylation, we performed an analysis of TSDR demethylation. A panel of the FoxP3 loci (ADS779, ADS657, ADS569, ADS442, ADS443, ADS1183, ADS1184) between WT and NAC1/- Tregs were analyzed by the Targeted NextGen Bisulfite Sequencing (tNGBS) (Fig. 5A), and the CpG DNA methylation of FoxP3 in the four regions including Distal Region (ADS657, ADS569), Proximal Region (ADS1183), CNS2 Region (ADS443), and 3' Downstream Region (ADS1184) were determined (Fig. 5B). No substantial differences of the CpG DNA methylation in the four regions were found between WT and NAC1 ${ }^{-/-}$Tregs (Fig. 5C, and Extended Table 1). The two bar graphs representing the specific methylation percentages of each FoxP3 $\mathrm{CpG}$ in $\mathrm{WT}$ and $\mathrm{NAC1}^{-/-}$Tregs are comparably presented (Fig. 5D). These results indicate that NAC1 does not have detectable effects on epigenetic imprinting in the TSDR region of FoxP3.

\section{FoxP3 transcription in Tregs is unaltered in the absence of NAC1}

As NAC1 is a transcription co-regulator, we wanted to know whether NAC1 affects the transcription of FoxP3. To compare FoxP3 transcription in Tregs with or without NAC1, we first examined the possible enrichment and direct binding of NAC1 at FoxP3 genetic locus in WT Tregs, using the chromatin immunoprecipitation coupled with deep sequencing (ChIP-seq). NAC1-associated chromatins were pulled down from the $\mathrm{CD} 4{ }^{+} \mathrm{CD} 25^{+}$Tregs of $\mathrm{C} 57 \mathrm{BL} / 6 \mathrm{mice}$, followed by a high throughput sequencing. The results showed that peak density of NAC1 was not 
enriched within regulatory elements of FoxP3 (Extended Fig. 6; Fig. 6Ai). Assay for transposase accessible chromatin sequencing (ATAC-seq) identified a total of over 10000 differential ATACseq peaks in WT and $\mathrm{NAC1}^{-/-}$Tregs, but no significantly differential accessibility was found at FoxP3 gene locus (Fig. 6Aii). FoxP3 ChIP-seq validated that FoxP3 enrichment was not affected by NAC1 expression (Fig. 6Aiii). Furthermore, the RNA-seq showed that among $\sim 200$ differentially expressed genes, FoxP3 was not differentially expressed in WT and $\mathrm{NAC1}^{-/-}$Tregs

(Fig. 6B). These results suggest that the effect of NAC1 on FoxP3 expression is not mediated at transcription level.

\section{NAC1 confines FoxP3 expression by promoting its deacetylation and destabilization}

Notably, our comparison of the FoxP3 ${ }^{+}\left(\mathrm{YFP}^{+}\right)$Tregs with the FoxP3- $\left(\mathrm{YFP}^{-}\right) \mathrm{CD}^{+}{ }^{\mathrm{T}}$ cells from FoxP3-IRES-mRFP (FIR) reporter mice revealed that the FoxP3 ${ }^{+}$Tregs expressed a low level of NAC1 but a high level of FoxP3; by contrast, the FoxP3- $\mathrm{CD}^{+} \mathrm{T}$ cells had a high expression of NAC1 (Fig. 7A). Ectopic expression of NAC1 (Fig. 7B) in WT Tregs resulted in a reduction of FoxP3 protein (Fig. 7C). These results disclose an inverse relationship between the expression of NAC1 and FoxP3 in Tregs. Moreover, co-localization of NAC1 and FoxP3 was observed in the nuclei of Tregs (Fig. 7D) and iTregs (Extended Fig. 7). These results suggest that NAC1 confines FoxP3 expression.

Post-translational modifications such as acetylation have a critical role in preventing proteasome-mediated degradation of FoxP3 and maintaining its functional activity $(19,20)$, and in our previous study we found that NACl can promote deacetylation of certain protein through its interaction with histone deacetylases (7). Thus, the acetylation of FoxP3 protein in $\mathrm{NAC1}^{-/}$ Tregs and WT Tregs was examined. Fig. 7E and Fig. 7F show that both FoxP3 and acetylated 
FoxP3 proteins were upregulated in $\mathrm{NAC1}^{-/-}$Tregs as compared with the WT Tregs; in particular, acetylation of FoxP3 was robustly enhanced in $\mathrm{NAC1}^{-/-}$Tregs than that of the WT Tregs (Fig. 7F). Conspicuously, in the Tregs treated with the pro-inflammatory cytokines IL-1 $\beta$ or TNF- $\alpha$, a vigorous increase of NAC1 expression but evident decreases of both FoxP3 (Fig. 7G) and acetylated FoxP3 were observed (Fig. 7H). Therefore, it is likely that stabilization of the acetylated FoxP3 protein accounts for the elevated amount of this key transcription factor in $\mathrm{NAC}^{-/}$Tregs, and in the Tregs treated with pro-inflammatory cytokines, up-regulation of NAC1 may induce deacetylation and destabilization of FoxP3. Indeed, the pulse-chase experiments demonstrated that the turnover of FoxP3 protein was 4-fold faster in WT Tregs than that in the NAC1 ${ }^{-/}$Tregs, with a half-life $\left(\mathrm{t}_{1 / 2}\right)$ of $4 \mathrm{hrs}$ and $8 \mathrm{hrs}$, respectively (Fig. 7I). Histone deacetylases (HDACs) have been reported to modulate the suppressive function of Tregs (21); therefore, we determined which HDAC may be involved in the NAC1-induced FoxP3 acetylation. We examined the expressions of HDAC6, HDAC9 and HDAC11, the deacetylases known to affect the stability of FoxP3 and Treg fitness (22). We demonstrated the comprised HDAC9 expression in $\mathrm{NAC1}^{-/-}$Tregs as compared to WT Tregs, but did not detect the direct interaction between NAC1 and HDAC9 (Fig. 7J). Our results suggest a role of HDAC9 in regulation of the NAC1-mediated FoxP3 stability. Collectively, these results imply that NAC1 negatively regulates FoxP3 stability via its effect on deacetylation of this protein, thus weakening immune tolerance. 


\section{Discussion}

Autoimmune diseases such as type 1 diabetes, rheumatoid arthritis, ulcerative colitis and Crohn's disease are presumed to result from interaction between genetic and environmental factors and to be a consequence of compromised immune tolerance versus adaptive immune response; yet, how impaired balance between immune response and tolerance is triggered as well as the mechanisms by which tolerance is established and maintained remain elusive. How the stability of FoxP3 and suppressor Tregs are regulated is an important theme in Treg biology. Using CRISPR screening, a recent study revealed several modulators of FoxP3 expression, and these modulators might be further explored as potential targets for immunotherapy (23). In this study, we identified $\mathrm{NAC1}$ as a critical determinant of immune tolerance. We show that $\mathrm{NAC}^{-/-}$mice is substantial tolerant to the induction of autoimmunity, as evidenced by the significantly decreased occurrences of autoimmune arthritis and colitis (Fig. 4). We further show that the promotive effect of NAC1 on autoimmunity is mediated through its negative regulation of the stability of Treg and FoxP3 (Fig. 7).

Although DNA methylation of FoxP3 has been reported to be associated with the stability and function of Tregs (24-27), the effects of NAC1 on Tregs do not appear to be associated with alterations in DNA methylation of FoxP3. We compared the DNA methylation of FoxP3 in WT and $\mathrm{NAC1}^{-/-}$Tregs and examined the DNA methylation of FoxP3 in the Treg-specific demethylated region (TSDR) of CNS2 (ADS443) and FoxP3 proximal promoter region (ADS1183) (Fig. 5). As a control, FoxP3 DNA methylation was similar in the unsorted lymphocytes from the LNs and spleen of $\mathrm{NAC1}^{-/-}$mice (Extended Data Table 1). In these experiments, greater than $100 \mathrm{CpG}$ sites in the FoxP3 DNA promoter regions showed that there was no significant difference between $\mathrm{WT}$ and $\mathrm{NAC1}^{-/-}$Tregs, indicating that NAC1 does not 
affect the DNA methylation of FoxP3. Moreover, we found that NAC1 does not act as a transcriptional regulator (Fig. 6). Instead, we show that NAC1 can interfere the acetylation and degradation of FoxP3 protein. (Fig. 7). Thus, the role of NAC1 in the post-transcriptional regulation of FoxP3 may account for the upregulation of FoxP3 in $\mathrm{NAC1}^{-/-}$Tregs.

Treg stability is vital to the maintenance of immune tolerance but is often altered in autoimmunity; yet, how destabilization of Tregs occurs in autoimmune diseases remains elusive. In autoimmune arthritis, $\mathrm{TNF}-\alpha$ plays a more important role in triggering events leading to inflammation both locally and systemically, whereas IL-1 is more involved at the local level in the processes leading to cartilage and bone destruction and in impeding cartilage repair. Nevertheless, IL-1 and TNF- $\alpha$ strongly synergize in numerous biological functions, and simultaneous blockade of IL-1 and TNF- $\alpha$ provides favorable effects in suppressing arthritis development, suggesting the importance of both of the cytokines $(28,29)$. Our results reported here, which show the concomitant upregulation of NAC1 and downregulation of FoxP3 in Tregs treated with the pro-inflammatory cytokines such as IL-1 $\beta$ and TNF- $\alpha$ (Fig. $7 \mathbf{H})$, provide at least a partial explanation for this question. Based on these findings, we speculate that the "basal" level of NAC1 in Tregs plays an important role in leashing the immune tolerance to keep the immune system vigilant to pathogens; inflammatory stimulation induces upregulation of NAC1, and this in turn destabilizes FoxP3 and converts FoxP3 ${ }^{+}$Tregs to FoxP3- Tregs that then become Th1 or Th17 CD4 ${ }^{+}$Teffs, further breaking tolerance and instigating strong immune response (Fig. 7K). In this study, the role and importance of the NAC1-mediated regulation of FoxP3 in Tregs were largely determined in mice with complete knockout of NAC1 gene. We demonstrated that NAC1 can modulate the stability of FoxP3 protein, and loss of NAC1 enhances the functional activity of Tregs. It shall be interesting to further investigate the functions of NAC1 in 
hematopoietic cells. Our data showing that NAC1 deletion is associated with reduced effector cell activity (Extended Data Figs. 2 and 3) open a question of whether impairment of the effector responses is also involved in the reduced inflammation caused by NAC1 deletion. The roles of NAC1 in other immune cells such as $\mathrm{CD}^{+} \mathrm{T}$ and $\mathrm{CD}^{+} \mathrm{Th} 1$ or Th17 effector cells warrant further investigation.

Because the mice that we used in this study were subjected to complete knockout of NAC1 gene, the deficiency of NAC1 in other cell types may also affect immune tolerance. For example, the role of $\mathrm{NAC} 1$ in other types of $\mathrm{T}$ cells such as $\mathrm{CD}^{+} \mathrm{T}$ cells, conventional $\mathrm{CD} 4^{+} \mathrm{T}$ cells (i.e., Th1, Th2, Th17) and innate immune cells including macrophages and dendritic cells remain unclear. To exclude the possibility that NAC1 deficiency in other types of cells may impact Treg development, we performed the bone marrow chimera experiment in which the bone marrow cells $\left(\mathrm{CD}^{-} \mathrm{CD}^{-}\right)$from WT and $\mathrm{NAC1}^{-/-}$mice were transferred into X-ray-irradiated WT mice, and 6 weeks later, we euthanized the mice and isolated the spleen, LNs and thymus for examining Treg development. These experiments showed the comparable numbers of Tregs in the thymus of the chimera receiving either WT or $\mathrm{NACl}^{-/-}$bone marrow cells. However, we observed that the bone marrow transplants from $\mathrm{NAC1}^{-/-}$mice generated greater numbers of Tregs in the LNs and spleen than those from WT (Extended Fig. 8), which is similar to that we classified in $\mathrm{NAC1}^{-/-}$mice. This result also supports the conclusion that in the peripheral system, $\mathrm{NAC1}^{-/}$Tregs are more stable than WT cells.

As the stability of Tregs is vital to maintenance of immune tolerance, the role of NAC1 in destabilization of suppressor Tregs provides a promising opportunity for therapeutic manipulation of their stability and function. We believe that therapeutic targeting of NAC1 to revitalize suppressor Tregs may be further exploited as a potentially novel tolerogenic strategy to treating 
autoimmune diseases. We have recently identified and characterized a small molecule inhibitor of NAC1, NIC3, through a high-throughput screening, and showed that this compound can effectively promote the proteasome-mediated degradation of NAC1 protein (30). We anticipate that inhibiting NAC1 by pharmacologic approaches shall provide further insights into the feasibility and effectiveness of NAC1-based modulation of Tregs stability for therapeutic purposes. 


\section{Methods}

\section{Cell lines and mice}

C57BL/6 (B6), Rag1 ${ }^{-/}$and FOXP3-IRES-mRFP (FIR) reporter mice were purchased from The Jackson Laboratory (Bar Harbor, ME). NAC1 ${ }^{-/}$mice were generated by Dr. Jian-long Wang and crossed in the C57BL/6 background for more 10 generations $(6,31)$. All the animal experiments were performed in compliance with the regulations of The Texas A\&M University Animal Care Committee (IACUC) and in accordance with the guidelines of the Association for the Assessment and Accreditation of Laboratory Animal Care.

\section{T cell culture}

T cells were cultured in 48-well plates containing $1 \mathrm{ml}$ RPMI 1640 (Invitrogen) with 10\% fetal calf serum (Omega Scientific, CA). T cell isolation kits including mouse CD4+ (\# 130-104-454), $\mathrm{CD}^{+} \mathrm{a}^{+}(\# 130-104-075)$ and CD4 ${ }^{+}$CD25 ${ }^{+}$Treg (\#130-091-041), T cell activation/expansion kit (\#130-093-627) and Treg expansion kit (\#130-095-925) were purchased from the Miltenyi Biotec (Auburn, CA). Recombinant mouse TGF- $\beta$ (\#763104), IL-1 $\beta$ (\#575106), and TNF- $\alpha$ (\#575206) were obtained from BioLegend (San Diego, CA).

\section{Cytokine secretion, cell recovery, and proliferation/cell division}

IL-2 and IFN- $\gamma$ were measured using ELISA after $48 \mathrm{hr}$ of culture (32). Latent TGF- $\beta 1$ (\#433007, BioLegend) and IL-10 (\#431411, BioLegend) were determined using ELISA after 48 hr of stimulation. In vitro $\mathrm{T}$ cell survival was determined using trypan blue exclusion. Proliferation/division of T cells was measured using the CellTrace ${ }^{\mathrm{TM}}$ CFSE Cell Proliferation Kit (\#C34554, Invitrogen). 


\section{Metabolic assays}

Purified $\mathrm{CD}^{+}$Tregs were plated in the Cell-Tak-coated Seahorse Bioanalyzer XFe96 culture plates $(300,000$ or 100,000 cells/well, respectively) in assay medium consisting of minimal, unbuffered DMEM supplemented with 1\% BSA and $25 \mathrm{mM}$ glucose, $2 \mathrm{mM}$ glutamine (and $1 \mathrm{mM}$ sodium pyruvate for some experiments). Basal rates were taken for $30 \mathrm{~min}$, and then streptavidincomplexed anti-CD3bio at $3 \mathrm{mg} / \mathrm{mL} \pm$ anti-CD28 at $2 \mathrm{mg} / \mathrm{mL}$ or PMA (CAS 16561-29-8) (Fisher) was injected and readings were taken for 1-6 hr. In some experiments, oligomycin (2 mM), carbonyl cyanide p-trifluoromethoxyphenylhydrazone (FCCP) $(0.5 \mathrm{mM}), 2$-deoxy-d-glucose (10 $\mathrm{mM})$ and rotenone/antimycin $\mathrm{A}(0.5 \mathrm{mM})$ were injected to obtain maximal respiratory and control values. Because ECAR values tend to vary among experiments, both a representative trace and normalized data (calculated as the difference between maximal and basal ECAR values) were shown in the figures.

\section{In vitro mouse Treg generation}

Naive $\mathrm{CD}^{+} \mathrm{CD} 25^{-} \mathrm{T}$ cells from the $\mathrm{LNs}$ and spleen of $\mathrm{WT}$ or $\mathrm{NAC1} 1^{-/}$mice were incubated with the indicated reagents including TGF- $\beta$ in the CellXVivo ${ }^{\mathrm{TM}}$ Mouse Treg Cell Differentiation Kit (\#CDK007, R\&D Systems) for 5 days.

\section{In vitro Treg suppression assay}

$\mathrm{CD}^{+} \mathrm{CD} 25^{+}$Tregs were co-cultured with the CFSE-labeling CD4 ${ }^{+} \mathrm{CD} 25^{-}$responder $\mathrm{T}$ cells from the pooled LNs and spleen of C57BL/6 mice in various ratios. To stimulate $\mathrm{T}$ cells, the mixed T cells were treated with the $\mathrm{T}$ cell activation/expansion kit (\#130-093-627; Miltenyi Biotec). As 
controls, $\mathrm{CD}^{+} \mathrm{CD}^{+} 5^{+}$Tregs and $\mathrm{CD} 4^{+} \mathrm{CD} 25^{-}$responder $\mathrm{T}$ cells were cultured without any stimulus. Suppression of responder T cells was determined by measuring CFSE dilution.

\section{T cell transfer model of colitis}

Naive $\mathrm{CD}^{+} \mathrm{T}$ effectors (Teffs, $\mathrm{CD}^{+} 5 \mathrm{RB}^{\mathrm{hi}} \mathrm{CD} 25^{-}$) from $\mathrm{B} 6$ mice and $\mathrm{CD}^{+}$Tregs $\left(\mathrm{CD} 45 \mathrm{RB}^{\mathrm{lo}} \mathrm{CD} 25^{+}\right)$from WT or $\mathrm{NAC1}^{-/-}$mice were purified using a high-speed cell sorter. Naive $\mathrm{CD}^{+}$Teffs $\left(6 \times 10^{5}\right.$ cells/mouse $)$ without or with Tregs $\left(2 \times 10^{5}\right.$ cells/mouse $)$ were then i.p. transferred into $\mathrm{Rag}^{-/-}$mice. Body weights were recorded twice a week. When loss of body weight exceeded $20 \%$ after transfer, the host mice were sacrificed.

\section{Retroviral transduction}

Full-length cDNA of NAC1 was provided by Dr. Ie-Ming Shih and Tian-Li Wang (John Hopkins University (33), and subcloned into the Mig vector containing GFP for retroviral transduction of mouse Tregs (34).

\section{Antibodies and reagents}

PE-, PE/Cy7, Alexa 647, APC or APC/Cy7-conjugated anti-mouse CD4 (GK1.5), CD8 (53-6.7), CD25 (3C7), CD45RB (C363-16A), CD25 (3C7), CD44 (IM7), CD117 (2B8), TCRVß (H57597), TGF- $\beta 1(T W 7-16 B 4)$, FoxP3 (MF-14) and Acetylated Lysine (15G10; \#623402) were purchased from BioLegend (San Diego, CA). Rabbit NAC1 (\#4183), HDAC6 (\#7612) and $\beta$-actin (\#8457) antibodies were purchased from Cell Signaling (Beverly, MA). Rabbit anti-NAC1 antibody (ab29047) for immunoprecipitation was obtained from Abcam (Cambridge, MA). Mouse HDAC9 (\#sc-398003) and HDAC11 (\#sc-390737) antibodies were purchased from Santa Cruz 
Biotech (Dallas, TX). Cycloheximide were purchased from Sigma-Aldrich Corporation (SigmaAldrich, St Louis, MI).

\section{Immunoprecipitation and Immunoblotting}

Cells were lysed in ice-cold RIPA Lysis Buffer (\#89900, Thermo Scientific, MA) for 30 min. Insoluble materials were removed, and the lysates were used for Western blotting or immunoprecipitated overnight with an antibody such as anti-FoxP3 antibody followed by incubation with protein $\mathrm{G}$ agarose beads at $4^{\circ} \mathrm{C}$ for $2 \mathrm{hr}$. The washed immunoprecipitates were boiled in SDS sample buffer and the protein content was determined by Bio-Rad protein assay kit (\#5000002, Bio-Rad, Hercules, CA). Equal amounts (30-50 $\mu \mathrm{g})$ were loaded onto 4-12\% NuPage Bis-Tris pre-casting gels (SDS-PAGE), transferred onto PVDF membrane (Invitrogen), and immunoblotted. All blots were developed with the ECL immunodetection system (\#426319, BioLegend, CA).

\section{RT-PCR}

Retrovirally transduced Tregs with Mig or Mig-NAC1 were unsorted or sorted, and total RNA was extracted from the Tregs using QIAgen RNeasy mini kits. Samples were subjected to reverse transcription using a high-capacity cDNA synthesis kit (Applied Biosystems). PCR analysis was performed using TaqMan real-time PCR (Thermo Fisher Scientific). Primers used are: FoxP3

forward: 5'-CCCAGGAAAGACAGCAACCTT-3', FoxP3 reverse: 5'TTCTCACAACCAGGCCACTTG-3'; NAC1 forward: 5'-TGC TTA GTT AAC TTA CTG CAG GGC TTC AGC CGA-3', NAC1 reverse: 5'-TAA GCA CTC GAG ATG GCC CAG ACA CTG CAG ATG-3'. 


\section{CpG DNA methylation}

CpG DNA methylation was analyzed by bisulphite treatment of RNase-treated genomic DNA, followed by PCR amplification and pyrosequencing (Pyro Q-CpG), which was performed by EpigenDX. Eight mouse genes, including FoxP3, Ctla4, Ikzf2, Ikzf4, Tnfrsf18, Il2ra, Cd274 and Irf4, were screened for methylation percentage in various regulatory regions. Sequences analyses for FoxP3 were: FoxP3 promoter, FoxP3 CNS2 and FoxP3 3' region.

\section{RNA-Seq}

Tregs were mechanically disrupted and homogenized using a Mini-BeadBeater-8 (BioSpec Products, Bartlesville, Oklahoma). RNA was extracted using a RNeasy Mini Kit (Qiagen, Valencia, California). RNA concentration and integrity were measured using an Agilent 2100 Bioanalyzer (Agilent Technologies, Santa Clara, CA). All samples had an RNA Integrity Value (RIN) of $>7.5$. RNA-Seq libraries were prepared using the Illumina TruSeq Stranded mRNA Library Prep Kit (Illumina, San Diego, CA) and sequenced on an Illumina HiSeq 2500 Sequencer (Illumina, San Diego, CA) as 75 base pair (bp) paired-end reads.

\section{CHIP-seq}

ChIP was performed as described (35), with some modifications. Tregs were subjected to sonication using a Bioruptor ${ }^{\circledR}$ Pico sonication device (Diagenode) to obtain 100-500-bp chromatin fragments. A total of $250 \mu \mathrm{g}$ of sonicated chromatin fragments were incubated with 10 $\mu \mathrm{g}$ of NAC1 antibody for crosslinking with magnetic beads (no. 11201D, Dynabeads® M280 sheep anti-mouse IgG, Dynal Biotech, Invitrogen). The cross-linked samples were reversed at 
$65^{\circ} \mathrm{C}$ for overnight, and the precipitated DNA was treated with RNase A and proteinase $\mathrm{K}$, and then purified using the QIAquick PCR purification kit (QIAGEN). The DNA libraries were prepared following the guidelines from Illumina (Fasteris Life Sciences; Plan-les-Ouates, Switzerland). Input DNA was sequenced and used as a control. The DNA libraries were sequenced on Illumina HiSeq2500, producing 25-35 million reads per sample.

\section{ATAC-Seq}

Tregs were freshly dissected and processed for ATAC-seq. In brief, the tissues were resuspended in $1 \mathrm{ml}$ of lysis buffer (1× PBS, $0.2 \% \mathrm{NP}-40,5 \%$ BSA, $1 \mathrm{mM} \mathrm{DTT}$, protease inhibitors $)$, followed by Dounce homogenization with a loose pestle using 20 strokes. The lysates were then filtered through a $40-\mu \mathrm{m}$ cell strainer, and the nuclei were collected by centrifugation at $500 \mathrm{~g}$ for $5 \mathrm{~min}$. Tagmentation was performed immediately according to the reported ATAC-seq protocol (36).

\section{Pulse-chase analysis}

Isolated Tregs from WT or NAC1 ${ }^{-/-}$mice were activated and expanded with kits (\# 130-104-454 and \#130-095-925; Miltenyi Biotec), then treated with cycloheximide (150 $\mu \mathrm{g} / \mathrm{ml})$ for various periods of time. FoxP3 protein was analyzed by immunoblotting.

\section{Collagen-induced arthritis}

C57BL/6 mice (4 months old) were injected at the base of the tail with $0.1 \mathrm{~mL}$ of emulsion containing $100 \mu \mathrm{g}$ of bovine type II collagen (CII) (Chondrex, Redmond, WA, USA) in complete Freund's adjuvant (CFA) (Chondrex), using a 1-mL glass tuberculin syringe with a 26-guage needle. Mice were assessed for arthritis in the paws (37). 


\section{DSS-induced colitis}

Colitis was induced in mice by oral ingestion of 3\% dextran sulfate sodium (DSS, SKU 02160110 CF; MP Biomedicals) in drinking water for 5 days. The severity of colitis activity was graded on designated dates as described (38). Body weight, occult or gross rectal bleeding, and feces consistency (on scales of $0-4$ ) were monitored for each mouse. The resultant IBD disease activity index is the average of the scores of the colitis symptoms. The occult blood in mouse fecal samples was detected using Hemoccult Test Kit (Beckman Coulter Inc, Fullerton, CA).

\section{Histology and immunohistochemistry}

Joint or gut tissues were fixed with 10\% neutral formalin solution (VWR, West Chester, PA), and the fixed samples were prepared and stained with H\&E as described (39). For immunofluorescent microscopy, the tissues were frozen in cryovials on dry ice immediately following resection. Cryosectioning and immunofluorescent staining were performed as described (39).

\section{Statistical analysis}

Multiple unpaired $t$-test, simple linear regression and survival curve comparison were performed to analyze the differences between the groups, using GraphPad Prism (GraphPad Software, San Diego, CA); significance was set at 5\%. 


\section{Extended Methods}

\section{Reagents}

H-2K ${ }^{\mathrm{b}}$ VACV B8R (TSYKFESV) Tetramer (\#TB-M538-1, MBL), anti-mouse CD36 antibody (clone HM36, BioLegend), anti-human/mouse/rat NAC1 antibody (clone SWN-3, BioLegend), anti-human FoxP3 antibody (clone 206D, BioLegend), and L-(+)-Lactic acid (\#ICN19022805, MP Biomedicals).

\section{Viral infection}

VACV infection was performed by an intraperitoneal injection of viruses $\left(2 \times 10^{6} \mathrm{PFU} / \mathrm{mouse}\right)$ as described (40).

\section{Murine Melanoma Model}

WT or NAC1 $1^{-/-}$Tregs $\left(1 \times 10^{5}\right)$ were injected s.c.in the flank region of the recipient mice inoculated with $1 \times 10^{6}$ B16 tumor cells. Tumor sizes were measured by a caliper and tumor volumes were calculated as: $\mathrm{V}=$ long diameter $\times$ short diameter $^{2} \times 0.52(41)$.

\section{LPS-induced colitis}

To induce colitis, B6.Thy1.1 Tg mice were i.p. injected with $20 \mu \mathrm{g} / \mathrm{kg}$ LPS. In the following day, $3 \times 10^{6} \mathrm{WT}$ or $\mathrm{NAC1}^{-/-}$Tregs were i.v. transferred into LPS-challenged mice via the tail vein. Seven days later, mice were sacrificed and the colons and spleens of the mice were dissociated. The length of colon was measured, and the colons were processed for H\&E staining and flow cytometric analysis. 


\section{Generation of bone marrow chimera}

To prepare B6. Thy $1.1^{+} \mathrm{Tg}$ recipient mice for irradiation, drinking water was removed $12 \mathrm{hrs}$ prior to irradiation. The mice were then X-ray irradiated (1000 rad) with a RS200 X-ray irradiator (Rad Source Technologies Inc. GA, USA). The bone marrow cells were harvested from femur of C57BL/6 Thy $1.2^{+} \mathrm{WT}$ and $\mathrm{NAC1}^{-/-}$mice, using standard procedures. Red blood cells (RBCs) were lysed, and $\mathrm{CD}^{+}$cells and $\mathrm{CD}^{+}$cells were depleted by the negative selection using biotin conjugated anti-CD4 and anti-CD8 antibodies and streptavidin nanobeads. $\mathrm{CD}^{+}$and $\mathrm{CD} 8^{+}-$ depletions were analyzed by flow cytometry. Ten millions of CD4/CD8-depleted WT and NAC1-

/- bone marrow cells were i.v. injected into the irradiated B6.Thy $1.1^{+}$recipient mice. Sulfatrim (sulfamethoxazole and trimethoprim oral suspension)-containing drinking water $(5 \mathrm{ml} / 200 \mathrm{ml})$ was given to the irradiated animals for 2 weeks. After 6 weeks, the spleen, LNs and thymus were isolated, and cells were analyzed by flow cytometry to evaluate the development of Tregs. 


\section{Author contributions}

J.Y. and J.S. designed the experiments, analyzed the data, and wrote this paper. Y.R., A.K., X.X., JK.D., H.P., L.W., Y.Z. C.J., Y.C., and L.Z. performed the experiments. D.F., RC.A., P.dF. and J. W. provided reagents or NAC1 $1^{-/}$mice. X.X., JK.D., H.P., Y.Z., C.J., L.Z., X.L and Y.C. analyzed the data.

\section{Acknowledgments}

This work was supported by National Cancer Institute Grant R01CA221867 to JM. Yang and J.S., and National Institute of Health Grant R01AI121180 and R21AI128325, the American Diabetes Association (1-16-IBS-281), and Department of Defense Grant LC210150 to J.S.

\section{Guarantor's statement}

J.Y. and J.S. are the guarantors of this work and, as such, had full access to all the data in the study and takes responsibility for the integrity of the data and the accuracy of the data analysis.

\section{Conflict of interest}

The authors have declared that no conflict of interest exists. 


\section{References}

1. T. Alissafi, L. Kalafati, M. Lazari, A. Filia, I. Kloukina, M. Manifava, J. H. Lim, V. I. Alexaki, N. T. Ktistakis, T. Doskas, G. A. Garinis, T. Chavakis, D. T. Boumpas, P. Verginis, Mitochondrial Oxidative Damage Underlies Regulatory T Cell Defects in Autoimmunity. Cell metabolism 32, 591-604 e597 (2020).

2. X. Y. Cha, R. C. Pierce, P. W. Kalivas, S. A. Mackler, NAC-1, a rat brain mRNA, is increased in the nucleus accumbens three weeks after chronic cocaine self-administration. J Neurosci 17, 6864-6871 (1997).

3. J. Wang, S. Rao, J. Chu, X. Shen, D. N. Levasseur, T. W. Theunissen, S. H. Orkin, A protein interaction network for pluripotency of embryonic stem cells. Nature 444, 364-368 (2006).

4. J. Kim, J. Chu, X. Shen, J. Wang, S. H. Orkin, An extended transcriptional network for pluripotency of embryonic stem cells. Cell 132, 1049-1061 (2008).

5. T. Ma, Z. Wang, Y. Guo, D. Pei, The C-terminal pentapeptide of Nanog tryptophan repeat domain interacts with Nac1 and regulates stem cell proliferation but not pluripotency. $J$ Biol Chem 284, 16071-16081 (2009).

6. F. Faiola, N. Yin, M. Fidalgo, X. Huang, A. Saunders, J. Ding, D. Guallar, B. Dang, J. Wang, NAC1 Regulates Somatic Cell Reprogramming by Controlling Zeb1 and Ecadherin Expression. Stem Cell Reports 9, 913-926 (2017).

7. Y. Zhang, Y. J. Ren, L. C. Guo, C. Ji, J. Hu, H. H. Zhang, Q. H. Xu, W. D. Zhu, Z. J. Ming, Y. S. Yuan, X. Ren, J. Song, J. M. Yang, Nucleus accumbens-associated protein-1 promotes glycolysis and survival of hypoxic tumor cells via the HDAC4-HIF-1alpha axis. Oncogene 36, 4171-4181 (2017).

8. M. Liu, J. Zhang, B. D. Pinder, Q. Liu, D. Wang, H. Yao, Y. Gao, A. Toker, J. Gao, A. Peterson, J. Qu, K. A. Siminovitch, WAVE2 suppresses mTOR activation to maintain T cell homeostasis and prevent autoimmunity. Science 371, (2021).

9. E. W. Weber, K. R. Parker, E. Sotillo, R. C. Lynn, H. Anbunathan, J. Lattin, Z. Good, J. A. Belk, B. Daniel, D. Klysz, M. Malipatlolla, P. Xu, M. Bashti, S. Heitzeneder, L. Labanieh, P. Vandris, R. G. Majzner, Y. Qi, K. Sandor, L. C. Chen, S. Prabhu, A. J. Gentles, T. J. Wandless, A. T. Satpathy, H. Y. Chang, C. L. Mackall, Transient rest restores functionality in exhausted CAR-T cells through epigenetic remodeling. Science 372, (2021).

10. M. C. Fantini, S. Dominitzki, A. Rizzo, M. F. Neurath, C. Becker, In vitro generation of CD4+ CD25+ regulatory cells from murine naive T cells. Nat Protoc 2, 1789-1794 (2007).

11. H. Wang, F. Franco, Y. C. Tsui, X. Xie, M. P. Trefny, R. Zappasodi, S. R. Mohmood, J. Fernandez-Garcia, C. H. Tsai, I. Schulze, F. Picard, E. Meylan, R. Silverstein, I. Goldberg, S. M. Fendt, J. D. Wolchok, T. Merghoub, C. Jandus, A. Zippelius, P. C. Ho, CD36mediated metabolic adaptation supports regulatory $\mathrm{T}$ cell survival and function in tumors. Nat Immunol 21, 298-308 (2020).

12. N. H. Son, D. Basu, D. Samovski, T. A. Pietka, V. S. Peche, F. Willecke, X. Fang, S. Q. Yu, D. Scerbo, H. R. Chang, F. Sun, S. Bagdasarov, K. Drosatos, S. T. Yeh, A. E. Mullick, K. I. Shoghi, N. Gumaste, K. Kim, L. A. Huggins, T. Lhakhang, N. A. Abumrad, I. J. Goldberg, Endothelial cell CD36 optimizes tissue fatty acid uptake. J Clin Invest 128, 4329-4342 (2018). 
13. R. Haque, F. Lei, X. Xiong, Y. Bian, B. Zhao, Y. Wu, J. Song, Programming of regulatory $\mathrm{T}$ cells from pluripotent stem cells and prevention of autoimmunity. J Immunol 189, 12281236 (2012).

14. B. Chassaing, J. D. Aitken, M. Malleshappa, M. Vijay-Kumar, Dextran sulfate sodium (DSS)-induced colitis in mice. Curr Protoc Immunol 104, Unit 1525 (2014).

15. Y. Ruan, J. He, W. Wu, P. He, Y. Tian, L. Xiao, G. Liu, J. Wang, Y. Cheng, S. Zhang, Y. Yang, J. Xiong, K. Zhao, Y. Wan, H. Huang, J. Zhang, R. Jian, Nac1 promotes self-renewal of embryonic stem cells through direct transcriptional regulation of c-Myc. Oncotarget $\mathbf{8}$, 47607-47618 (2017).

16. M. Malleshaiah, M. Padi, P. Rue, J. Quackenbush, A. Martinez-Arias, J. Gunawardena, Nac1 Coordinates a Sub-network of Pluripotency Factors to Regulate Embryonic Stem Cell Differentiation. Cell Rep 14, 1181-1194 (2016).

17. N. Ohkura, Y. Yasumizu, Y. Kitagawa, A. Tanaka, Y. Nakamura, D. Motooka, S. Nakamura, Y. Okada, S. Sakaguchi, Regulatory T Cell-Specific Epigenomic Region Variants Are a Key Determinant of Susceptibility to Common Autoimmune Diseases. Immunity 52, 1119-1132 e1114 (2020).

18. K. A. Helmin, L. Morales-Nebreda, M. A. Torres Acosta, K. R. Anekalla, S. Y. Chen, H. Abdala-Valencia, Y. Politanska, P. Cheresh, M. Akbarpour, E. M. Steinert, S. E. Weinberg, B. D. Singer, Maintenance DNA methylation is essential for regulatory T cell development and stability of suppressive function. J Clin Invest 130, 6571-6587 (2020).

19. J. Geng, S. Yu, H. Zhao, X. Sun, X. Li, P. Wang, X. Xiong, L. Hong, C. Xie, J. Gao, Y. Shi, J. Peng, R. L. Johnson, N. Xiao, L. Lu, J. Han, D. Zhou, L. Chen, The transcriptional coactivator TAZ regulates reciprocal differentiation of TH17 cells and Treg cells. Nat Immunol 18, 800-812 (2017).

20. R. Nasrallah, C. J. Imianowski, L. Bossini-Castillo, F. M. Grant, M. Dogan, L. Placek, L. Kozhaya, P. Kuo, F. Sadiyah, S. K. Whiteside, M. R. Mumbach, D. Glinos, P. Vardaka, C. E. Whyte, T. Lozano, T. Fujita, H. Fujii, A. Liston, S. Andrews, A. Cozzani, J. Yang, S. Mitra, E. Lugli, H. Y. Chang, D. Unutmaz, G. Trynka, R. Roychoudhuri, A distal enhancer at risk locus 11q13.5 promotes suppression of colitis by Treg cells. Nature 583, 447-452 (2020).

21. S. W. Choi, E. Gatza, G. Hou, Y. Sun, J. Whitfield, Y. Song, K. Oravecz-Wilson, I. Tawara, C. A. Dinarello, P. Reddy, Histone deacetylase inhibition regulates inflammation and enhances Tregs after allogeneic hematopoietic cell transplantation in humans. Blood 125, 815-819 (2015).

22. U. H. Beier, T. Akimova, Y. Liu, L. Wang, W. W. Hancock, Histone/protein deacetylases control Foxp3 expression and the heat shock response of T-regulatory cells. Curr Opin Immunol 23, 670-678 (2011).

23. J. T. Cortez, E. Montauti, E. Shifrut, J. Gatchalian, Y. Zhang, O. Shaked, Y. Xu, T. L. Roth, D. R. Simeonov, Y. Zhang, S. Chen, Z. Li, J. M. Woo, J. Ho, I. A. Vogel, G. Y. Prator, B. Zhang, Y. Lee, Z. Sun, I. Ifergan, F. Van Gool, D. C. Hargreaves, J. A. Bluestone, A. Marson, D. Fang, CRISPR screen in regulatory T cells reveals modulators of Foxp3. Nature 582, 416-420 (2020).

24. Y. Zheng, S. Josefowicz, A. Chaudhry, X. P. Peng, K. Forbush, A. Y. Rudensky, Role of conserved non-coding DNA elements in the Foxp3 gene in regulatory T-cell fate. Nature 463, 808-812 (2010). 
25. S. E. Weinberg, B. D. Singer, E. M. Steinert, C. A. Martinez, M. M. Mehta, I. MartinezReyes, P. Gao, K. A. Helmin, H. Abdala-Valencia, L. A. Sena, P. T. Schumacker, L. A. Turka, N. S. Chandel, Mitochondrial complex III is essential for suppressive function of regulatory T cells. Nature 565, 495-499 (2019).

26. W. Y. Tseng, Y. S. Huang, F. Clanchy, K. McNamee, D. Perocheau, J. Ogbechi, S. F. Luo, M. Feldmann, F. E. McCann, R. O. Williams, TNF receptor 2 signaling prevents DNA methylation at the Foxp3 promoter and prevents pathogenic conversion of regulatory $\mathrm{T}$ cells. Proc Natl Acad Sci U S A 116, 21666-21672 (2019).

27. K. A. Helmin, L. Morales-Nebreda, M. A. T. Acosta, K. R. Anekalla, S. Y. Chen, H. Abdala-Valencia, Y. Politanska, P. Cheresh, M. Akbarpour, E. M. Steinert, S. E. Weinberg, B. D. Singer, Maintenance DNA methylation is essential for regulatory T cell development and stability of suppressive function. J Clin Invest 130, 6571-6587 (2020).

28. A. Levescot, M. H. Chang, J. Schnell, N. Nelson-Maney, J. Yan, M. Martinez-Bonet, R. Grieshaber-Bouyer, P. Y. Lee, K. Wei, R. B. Blaustein, A. Morris, A. Wactor, Y. Iwakura, J. A. Lederer, D. A. Rao, J. F. Charles, P. A. Nigrovic, IL-1beta-driven osteoclastogenic Tregs accelerate bone erosion in arthritis. J Clin Invest 131, (2021).

29. N. Meednu, J. Barnard, K. Callahan, A. Coca, B. Marston, R. Thiele, D. Tabechian, M. Bolster, J. Curtis, M. Mackay, J. Graf, R. Keating, E. Smith, K. Boyle, L. Keyes-Elstein, B. Welch, E. Goldmuntz, J. H. Anolik, Activated peripheral blood B cells in rheumatoid arthritis and relationship to anti-TNF treatment and response: randomized clinical trial for anti-TNF effects on B cells. Arthritis Rheumatol, (2021).

30. X. Wang, C. Ji, H. Zhang, Y. Shan, Y. Ren, Y. Hu, L. Shi, L. Guo, W. Zhu, Y. Xia, B. Liu, Z. Rong, B. Wu, Z. Ming, X. Ren, J. Song, J. Yang, Y. Zhang, Identification of a smallmolecule compound that inhibits homodimerization of oncogenic NAC1 protein and sensitizes cancer cells to anticancer agents. J Biol Chem 294, 10006-10017 (2019).

31. K. L. Yap, P. Sysa-Shah, B. Bolon, R. C. Wu, M. Gao, A. L. Herlinger, F. Wang, F. Faiola, D. Huso, K. Gabrielson, T. L. Wang, J. Wang, M. Shih Ie, Loss of NAC1 expression is associated with defective bony patterning in the murine vertebral axis. PLoS One 8, e69099 (2013).

32. J. Song, S. Salek-Ardakani, P. R. Rogers, M. Cheng, L. Van Parijs, M. Croft, The costimulation-regulated duration of PKB activation controls T cell longevity. Nat Immunol 5, 150-158 (2004).

33. K. Nakayama, N. Nakayama, B. Davidson, J. J. Sheu, N. Jinawath, A. Santillan, R. Salani, R. E. Bristow, P. J. Morin, R. J. Kurman, T. L. Wang, M. Shih Ie, A BTB/POZ protein, NAC-1, is related to tumor recurrence and is essential for tumor growth and survival. Proc Natl Acad Sci U S A 103, 18739-18744 (2006).

34. M. Haque, J. Song, K. Fino, P. Sandhu, X. Song, F. Lei, S. Zheng, B. Ni, D. Fang, J. Song, Stem cell-derived tissue-associated regulatory $\mathrm{T}$ cells ameliorate the development of autoimmunity. Sci Rep 6, 20588 (2016).

35. U. Ubaid, S. B. A. Andrabi, S. K. Tripathi, O. Dirasantha, K. Kanduri, S. Rautio, C. C. Gross, S. Lehtimaki, K. Bala, J. Tuomisto, U. Bhatia, D. Chakroborty, L. L. Elo, H. Lahdesmaki, H. Wiendl, O. Rasool, R. Lahesmaa, Transcriptional Repressor HIC1 Contributes to Suppressive Function of Human Induced Regulatory T Cells. Cell Rep 22, 2094-2106 (2018).

36. H. Yang, Y. Luan, T. Liu, H. J. Lee, L. Fang, Y. Wang, X. Wang, B. Zhang, Q. Jin, K. C. Ang, X. Xing, J. Wang, J. Xu, F. Song, I. Sriranga, C. Khunsriraksakul, T. Salameh, D. Li, 
M. N. K. Choudhary, J. Topczewski, K. Wang, G. S. Gerhard, R. C. Hardison, T. Wang, K. C. Cheng, F. Yue, A map of cis-regulatory elements and 3D genome structures in zebrafish. Nature 588, 337-343 (2020).

37. R. Haque, F. Lei, X. Xiong, Y. Wu, J. Song, FoxP3 and Bcl-xL cooperatively promote regulatory $\mathrm{T}$ cell persistence and prevention of arthritis development. Arthritis Res Ther 12, R66.

38. S. Wirtz, V. Popp, M. Kindermann, K. Gerlach, B. Weigmann, S. Fichtner-Feigl, M. F. Neurath, Chemically induced mouse models of acute and chronic intestinal inflammation. Nat Protoc 12, 1295-1309 (2017).

39. F. Lei, B. Zhao, R. Haque, X. Xiong, L. Budgeon, N. D. Christensen, Y. Wu, J. Song, In vivo programming of tumor antigen-specific $\mathrm{T}$ lymphocytes from pluripotent stem cells to promote cancer immunosurveillance. Cancer Res. 71, $4742-4747$ (2011).

40. S. Salek-Ardakani, M. Moutaftsi, S. Crotty, A. Sette, M. Croft, OX40 drives protective vaccinia virus-specific CD8 T cells. J Immunol 181, 7969-7976 (2008).

41. M. Haque, J. Song, K. Fino, P. Sandhu, Y. Wang, B. Ni, D. Fang, J. Song, Melanoma Immunotherapy in Mice Using Genetically Engineered Pluripotent Stem Cells. Cell transplantation 25, 811-827 (2016). 


\section{Figures and figure legends}

Figure 1. Loss of NAC1 impacts overall T cell populations. T cells from the thymus, peripheral lymph nodes (LNs) and spleen of $\mathrm{WT}$ or $\mathrm{NAC1}^{-/-}$mice were analyzed by flow cytometry and calculated for numbers or percentages. (A) CD4 and CD8 in the thymus. The double negative (DN) populations were analyzed for DN1 to DN4 stages based on CD44 and CD25. Data shown are the representative of five mice per group of three independent experiments. (B) Numbers and percentages of total thymocytes, CD4 or CD8 single positive (SP) and the percentages of DN2 or DN4 cells. Data shown are the representative of three identical experiments. The values represent mean \pm S.D. $\left(\mathrm{N}=4\right.$ or 5). ${ }^{* * * *}, p<0.0001$, ns, no difference, Student's unpaired $t$-test. (C) CD4 and CD8 T cells from the pooled LNs and spleen. Data shown are the representative of five mice per group of three independent experiments. ${ }^{* *}, p<0.001$, Student's unpaired $t$-test. (D) Numbers and percentages of T cells from the pooled LNs and spleen. Data shown are representative of three identical experiments. The values represent mean \pm S.D. $(\mathrm{N}=4$ or 5$) .{ }^{*}, p<0.05,{ }^{*}, p<0.01$, Student's unpaired t-test. (E) Representative $\mathrm{CD}^{+}{ }^{+}$FoxP3 ${ }^{+}$Tregs in the pooled LNs, spleen, blood, and thymus, gating on $\mathrm{CD}^{+}$populations. Data shown are the representative of three identical experiments $(\mathrm{N}=4$ or 5). (F) Numbers and percentages of Tregs. Data shown are the representative of three identical experiments. The values represent the mean \pm S.D. $(\mathrm{N}=4$ or 5$)$. ${ }^{* *}, p<0.001$; ns, no statistical difference, Student's unpaired $t$-test.

Figure 2. Loss of NAC1 enhances the induction of iTregs and expression of CD36. The naive $\mathrm{CD}^{+} \mathrm{CD} 25^{-} \mathrm{T}$ cells from the pooled spleen and $\mathrm{LNs}$ of WT or $\mathrm{NAC1}^{-/-}$mice were induced to iTregs in vitro in the presence of TGF- $\beta$ for 5 days. (A) Expression of NAC1 in naive CD4 and iTregs of WT T cells detected by immunoblots. (B) Expression of CD25 and FoxP3 in iTregs generated 
from WT and $\mathrm{NAC1}^{-/-} \mathrm{CD}^{+} \mathrm{CD} 25^{-} \mathrm{T}$ cells by flow cytometry. Data shown are the representative of three identical experiments. (C) Mean Fluorescence Intensity (MFI) of FoxP3 in iTregs generated from WT and $\mathrm{NAC1}^{-/-} \mathrm{CD} 4^{+} \mathrm{CD} 25^{-} \mathrm{T}$ cells as analyzed by flow cytometry. Results shown are the mean \pm S.D. of three identical experiments. ${ }^{* *}, p<0.01$, Student's unpaired $t$-test. (D) CD36 expression of WT or $\mathrm{NACl}^{-/}$iTregs following lactic acid treatment. Tregs generated in vitro were treated with $10 \mathrm{mM}$ lactic acid for various times and analyzed by flow cytometry for CD36 expression. Data shown are the representative of three identical experiments. (E) Quantification of percentage of $\mathrm{CD}^{+} 6^{+}$Tregs following lactic acid treatment. Results shown are the mean \pm S.D. of three identical experiments. $* * * P<0.001$, Student's unpaired $t$-test.

Figure 3. Loss of NAC1 enhances the functional activity of Tregs. Purified CD4 ${ }^{+}$Tregs from the pooled LNs and spleen of $\mathrm{WT}$ or $\mathrm{NAC1}^{-/-}$mice were stimulated with anti-CD3 plus CD28 antibodies in the presence of rIL-2 for various time. (A) Cell proliferation/division by CFSE-based flow cytometry. Data shown are the representative of three identical experiments. (B) \% and (C) numbers of cell recovery on various days were examined by trypan blue exclusion. The numbers of T cells present on day 0 were assigned a value of $100 \%$, and numbers surviving on various days were used to calculate the percentage recovery relative to day 0. Data shown represent the mean \pm S.E.M. of percentage change or numbers of three independent experiments. All $P>0.05$, Student's unpaired $t$-test). (D) Oxygen consumption rate (OCR, y axis) trace and tabulated data (right) of Tregs. ${ }^{*} P<0.05, * * * *, P<0.0001$, Student's unpaired $t$-test. (E) Glycolytic rate (glycoPER, y axis) trace and tabulated data (right) of Tregs. $* * * P<0.01, * * * *, P<0.0001$, Student's unpaired $t$-test. (F) Cytokine production of $16 \mathrm{hr}$ by intracellular staining. Data shown are the mean \pm S.D. of three independent experiments $(\mathrm{N}=3) . * * * P<0.001$; **** $P<0.0001$, Student's unpaired $t$-test. $(\mathbf{G})$ 
Cytokine secretion of $48 \mathrm{hr}$ by ELISA. Data shown are the mean \pm S.D. of three independent experiments $(\mathrm{N}=3) . * * P<0.01$, Student's unpaired $t$-test. $(\mathbf{H})$ In vitro suppressive assay. CD4 ${ }^{+}$ CD25/- Teffs pre-labelled with CFSE were non stimulated (control) or stimulated with anti-CD3 plus CD28 antibodies in the absence of WT or NAC1 ${ }^{-/-}$Tregs (10:1 or 2:1) for three days. Cell proliferation was analyzed by flow cytometry, gating on $\mathrm{CFSE}^{+}$population (left panel) and \% suppression was calculated (right panel). Data shown are the mean \pm S.D. of three independent experiments $(\mathrm{N}=3) .{ }^{* * *} P<0.001 ; * * * * P<0.0001$, Student's unpaired $t$-test. (I-J) $\mathrm{T}$ cell transfer model of colitis. (I) Changes of body weight of $\operatorname{Rag}^{-/-}$host mice after adoptive cell transfer of naive $\mathrm{CD}^{+}$Teffs with or without Tregs from WT or $\mathrm{NAC1}^{-/-}$mice. Data shown are the mean \pm S.E.M. of body weight change from a representative of three identical experiments $(\mathrm{N}=10) .{ }^{*}$, $p<0.05$, Nested $t$-test). (J) Representative H\&E-stained sections of gut tissues collected from the recipient mice 4 weeks after adoptive cell transfer. (K-N) LPS-mediated colitis. (K) Representative colon images of the LPS-induced colitis from two identical experiments $(\mathrm{N}=5)$. (L) Colon lengths in LPS-induced colitis. Data shown are the representative of two identical experiments $(\mathrm{N}=5)$. The values represent the mean \pm S.D. $* * P<0.01$, Student's unpaired $t$-test. (M) Representative H\&E-stained sections of images of proximal colon cross-section of mock or LPS-challenged B6.Thy1.1 Tg mice with transferred WT or NAC1 ${ }^{-/}$Tregs at day 8 of two identical experiments $(\mathrm{N}=5)$. ( $(\mathbf{N})$ Flow cytometric analysis of transferred $\mathrm{FoxP}^{+}$Tregs in draining LNs, gating on Thy $1.2^{+}$populations. Data shown are the representative of two identical experiments $(\mathrm{N}=5)$. ( $\mathbf{O}-\mathbf{Q})$ In vivo analyses of Tregs. WT and $\mathrm{NAC}^{-/-}$Tregs $\left(\right.$Thy $\left.1.2^{+}\right)$were labelled with CFSE and i.v. injected into B6.Thy1.1 Tg mice. On Days 2 and 5 after Treg transfer, the pooled LNs and spleen were analyzed for the transferred Th1.2 $2^{+}$Tregs by flow cytometry. (O) Proliferation by CFSE. Data shown are the representative of two identical experiments $(\mathrm{N}=5)$. 
(P) FoxP3 expression. Data shown are representative of two identical experiments $(\mathrm{N}=5)$. (C) Apoptosis analysis by Annexin V and PI. Data shown are the representative of two identical experiments $(\mathrm{N}=5)$.

Figure 4. $\mathrm{NAC1}^{-/-}$mice are tolerant to induction of autoimmunity. WT or $\mathrm{NACl}^{-/-}$mice were challenged with either bovine type II collagen in complete Freund's adjuvant by one intradermal immunization at two sites in the base and slightly above of the tail on day 0 , or by oral ingestion of 3\% dextran sulfate sodium (DSS, MP Biomedicals) in drinking water for 5 days. (A-C) Arthritis: The histology of the joints (A), arthritis incidence (B), and clinical score (C) were evaluated by examining the paws. Values are the mean \pm S.E.M. of three independent experiments $(\mathrm{n}=10) . P<0.0001$ in $\mathbf{B}$ and $\mathbf{C}$, simple linear regression. (D-H) Colitis: The severity of colitis activity was graded on the designated dates. Histology of colon (D), animal body weight change $(\mathbf{E})$, survival $(\mathbf{F})$, animal size and colon length $(\mathbf{G})$, and the resultant IBD disease activity index (H) were determined. Values are the mean \pm S.E.M. of three independent experiments $(\mathrm{n}=10)$. $P<0.0001$ in $\mathrm{E}$ and $\mathrm{H}$, simple linear regression. $P<0.001$ in $\mathrm{F}$, survival curve comparison.

Figure 5. CpG motif analyses indicate that FoxP3 DNA methylation is not regulated by NAC1. Naive WT and $\mathrm{NAC1}^{-/-} \mathrm{CD} 4{ }^{+} \mathrm{CD} 25^{+}$Tregs were purified and used in these analyses. (A) Diagram of mouse FoxP3 DNA methylation. Seven CpG sites of FoxP3 regulators (ADS657, ADS569, ADS1183, ADS442, ADS443, ADS779 and ADS1184) were analyzed. (B) Four CpG regions of FoxP3 regulators, including Distal Region (Regions ADS657 and ADS569), Proximal Region (ADS1183), CNS 2 Region (TSDR ADS443) and 3' downstream (ADS1184), were analyzed. (C) Genomic DNA of the lymphocytes from LNs and spleen of WT or NAC1 ${ }^{-/-}$mice 
was analyzed for methylation status of CNS2 (TSDR) and FoxP3 proximal promoter, respectively. The degree of methylation at each $\mathrm{CpG}$ motif is depicted according to the color code. (D) \% methylation of each FoxP3 CpG based on $(\mathbf{C})$. Data shown are the representative of two identical experiments.

Figure 6. Combined analyses of ChIP-seq, ATAC-seq and RNA-seq indicate that FoxP3 transcription is not regulated by NAC1. (Ai) NAC1 ChIP-seq. Approximately 100 differential peaks (NAC1 versus input) were identified using HOMER. NAC1 peak density was not enriched within the regulatory elements of FoxP3. The genes targeted by NAC1-enriched islands in WT Tregs were presented. Representative genomic regions (promotor and CNS1-3) show NAC1 enrichment. Normalized ChIP-seq reads (bigWig) and enriched islands (bed) are shown. (Aii) ATAC-Seq. Differential accessibility at FoxP3 gene locus in WT Tregs compared with NAC1/Tregs were presented. There were more than 10000 differential ATAC-seq peaks in total, but there were not any significant differential accessibility at FoxP3 gene locus in WT Tregs as compared with $\mathrm{NAC1}^{-/-}$Tregs. (Aiii) FoxP3 ChIP-seq. The genes targeted by FoxP3-enriched islands in WT or $\mathrm{NAC1}^{-/-}$Tregs were presented. (B) RNA-seq. FoxP3 was not differentially expressed in NAC1/- Tregs among 200 differentially expressed genes, i.e., FoxP3 gene was identically expressed in WT Tregs and $\mathrm{NAC1}^{-/-}$Tregs. All results shown are the representative of three identical experiments.

Figure 7. Upregulation of NAC1 by pro-inflammatory cytokines breaks immune tolerance via downregulation of FoxP3. (A) Expressions of NAC1, FoxP3 and $\beta$-actin in Tregs from the FIR reporter mice were analyzed by immunoblots. CD4 ${ }^{+}$Tregs from the LNs and spleen of the 
Foxp3-IRES-mRFP (FIR) reporter mice, WT or $\mathrm{NAC1}^{-/-}$mice, were analyzed. Data shown are the representative of three identical experiments. (B) NAC1 mRNA of WT Tregs generated in vitro and with ectopic expression of NAC1 were analyzed by RT-PCR. ***, $P<0.001$, Student's unpaired $t$-test. Data shown are the representative of three identical experiments. (C) FoxP3 protein of the sorted Tregs generated in vitro and with ectopic expression of NAC1 were analyzed by immunoblots. Data shown are the representative of three identical experiments. (D) Immunofluorescent staining of DAPI, NAC1 and FoxP3 in Tregs generated in vitro. Data shown are the representative of three identical experiments. (E) Expressions of FoxP3, NAC1 and $\beta$-actin in Tregs from WT and $\mathrm{NAC1}^{-/-}$mice were analyzed by immunoblots. Data shown are the representative of three identical experiments. (F) FoxP3 was immunoprecipitated from WT or $\mathrm{NAC1}^{-/-}$Tregs and examined for its Acetylation of Lysine (Pan Acetylation). Acetylated FoxP3 (upper panel), IgG control (middle panel) and FoxP3 (lower panel) were examined by immunoblotting. Data shown are the representative of three identical experiments. (G) WT Tregs were cultured in the presence of TGF- $\beta$, IL- $1 \beta$ or TFN- $\alpha$ for 12 hours, then the expressions of FoxP3, NAC1 and $\beta$-actin were analyzed by immunoblots. Data shown are the representative of three identical experiments. (H) WT Tregs were cultured in the presence of TGF- $\beta 1$ ( 2 ng/ml), IL$1 \beta(10 \mathrm{ng} / \mathrm{ml})$ or TFN- $\alpha(10 \mathrm{ng} / \mathrm{ml})$ for 12 hours, then FoxP3 was immunoprecipitated and examined for its acetylation. Acetylated FoxP3 (upper panel), IgG control (middle panel), and FoxP3 (lower panel) were examined by immunoblots. Data shown are the representative of three identical experiments. (I) The pulse-chase experiments. WT or $\mathrm{NAC1}^{-/-}$Tregs were treated with cycloheximide $(150 \mu \mathrm{g} / \mathrm{ml})$ for the indicated hours. FoxP3 protein level was analyzed by immunoblotting (upper panel); a plot indicated that with NAC1 deletion, the stability of FoxP3 was lifted in $\mathrm{NAC1}^{-/-}$Tregs compared to the WT group (lower graph). Data shown are the 
representative of two identical experiments. (J) HDAC expression in WT and NAC1 ${ }^{\text {-/ }}$ Tregs. Expression of HDAC6, HDAC9, HDAC11 and $\beta$-actin in WT and NAC1 ${ }^{-/}$Tregs was analyzed by immunoblotting (upper panel). FoxP3 was immunoprecipitated and the immunoprecipitates examined for HDAC9 (lower panel). Data shown are the representative of two identical experiments. (K) Proposed model of regulation of FoxP3 by NAC1 in immunity. 


\section{Legends to Extended Data}

\section{Extended Data Figure 1. NAC1 ${ }^{-/-}$mice have a decreased percentage of TCRV $\beta$ cells in DN4} stage. The thymocytes from $\mathrm{WT}$ or $\mathrm{NAC1}^{-/-}$mice were analyzed by flow cytometry and calculated for numbers or percentages. (A) CD117 and TCR V $\beta$. The DN populations were analyzed for CD117 and TCRV $\beta$. Data shown are the representative of three identical experiments. (B) TCRV $\beta$ and CD25. The DN4 populations were analyzed for TCR V $\beta$ and CD25. Data are the representative of three identical experiments $(\mathrm{N}=5) . *, p<0.05, * *, p<0.01, * * *, p<0.001$, Student's unpaired $t$ test.

Extended Data Figure 2. $\mathrm{NAC1}^{-/-} \mathrm{CD8}^{+} \mathrm{T}$ cells are defective in cytokine production and survival. (A-B) Percentages (A) and numbers (B) of $\mathrm{CD}^{+} \mathrm{T}$ cells from the pooled LNs and spleen of WT or $\mathrm{NAC1}^{-/-}$mice. Data shown are the representative of three identical experiments. The values represent mean \pm S.D. $(\mathrm{N}=3) .{ }^{*}, p<0.05$, Student's unpaired $t$-test. (C-D) Purified $\mathrm{CD}^{+} \mathrm{T}$ cells from the pooled LNs and spleen of $\mathrm{WT}$ or $\mathrm{NAC1}^{-/-}$mice were stimulated with antiCD3 plus CD28 antibodies. (C) Cytokine production. ${ }^{* *} p<0.01$, Student's unpaired $t$-test. The values represent the mean \pm S.D. $(\mathrm{N}=3)$. (D) Cell recovery on various days. The numbers of $\mathrm{T}$ cells present on day 0 were assigned a value of $100 \%$, and numbers surviving on various days were used to calculate the percentage recovery relative to day 0. Data shown are the mean \pm S.E.M. of percentage change of a representative of three identical experiments $(\mathrm{N}=3){ }^{* *}, p<0.01$, Nested $t$-test).

Extended Data Figure 3. Memory $\mathrm{CD8}^{+} \mathrm{T}$ cell development is altered in $\mathrm{NAC1}^{-/-}$mice. WT or $\mathrm{NAC1}^{-/-}$mice were challenged with VACV (i.p.) for 35 days, then the pooled LNs and spleen were 
analyzed by flow cytometry. (A) CD44 and VACV tetramer staining, gating on $\mathrm{CD}^{+} \mathrm{CD} 44^{+}$ population. (B) Quantification of percentage of memory $\mathrm{CD} 8^{+} \mathrm{T}$ cell populations. The results shown are the mean \pm S.E.M. of three identical experiments $(\mathrm{N}=5)$. ${ }^{* *} P<0.01$, Student's unpaired $t$-test.

\section{Extended Data Figure 4. Both $\mathrm{NAC1}^{-/-}$iTregs and nTregs produce more suppressive} cytokines than WT iTregs and nTregs. WT or $\mathrm{NACl}^{-/-}$iTregs and nTregs were examined productions of suppressive cytokines (IL-10 and TGF- $\beta$ ) by intracellular staining and flow cytometric analysis. (A) Productions of IL-10 and TGF- $\beta$. (B) MFI of IL-10 and TGF- $\beta$. Data shown are the representative of three identical experiments. $* P<0.05, * * *, P<0.0001, * * *$, $P<0.00001$, Student's unpaired $t$-test.

Extended Data Figure 5. NAC1 ${ }^{-/-}$Tregs show enhanced suppressive function. WT or NAC1 ${ }^{-/}$ Tregs $\left(1 \times 10^{5}\right)$ were injected s.c.in the flank region of the recipient mice with $1 \times 10^{6} \mathrm{~B} 16$ tumor cells on various days. (A) Tumor growth. Data shown are the mean \pm S.E.M. of tumor sizes of a representative of three identical experiments $(\mathrm{N}=6) . * * *, P<0.0001$, simple linear regression. (B) Survival curves. Data shown are the representative of three identical experiments $(\mathrm{N}=6)$. ns, $P>0.05$, Log-rank (Mantel-Cox) test.

\section{Extended Data Figure 6. FoxP3 elements regulated by NAC1 are located between Exon 2}

and Exon 8. ChIP-seq analysis of naive $\mathrm{CD} 4^{+} \mathrm{CD} 25^{+}$Tregs from the pooled LNs and spleen of WT mice. NAC1-enriched islands are shown. Representative genomic regions (Exon 2 and Exon 
8) show NAC1 enrichment. Normalized ChIP-seq reads (bigWig) and enriched islands (bed) are shown. Results shown are the representative of three identical experiments

\author{
Extended Data Figure 7. Co-localization of NAC1 and FoxP3 in the nuclei of Tregs. \\ Immunofluorescent staining of DAPI, NAC1 and FoxP3 in Tregs generated in vitro. Arrows \\ indicate overlays with DAPI, NAC1 and FoxP3. Data shown are the representatives of three \\ identical experiments.
}

Extended Data Figure 8. Thymic development of $\mathrm{NAC1}^{-/-}$Tregs in the bone marrow chimeras. Bone marrow cells $\left(\mathrm{CD}^{-\mathrm{CD}} 8^{-}\right.$; Thy $\left.1.2^{+}\right)$from $\mathrm{WT}$ and $\mathrm{NACl}^{-/-}$mice were transferred into X-ray irradiated mice $\left(\right.$ Thy $\left.1.1^{+}\right)$. Six weeks later, the mice were euthanized, and the spleen, LNs and thymus were isolated to examine Treg development using flow cytometry. (A) $\mathrm{CD}^{+}{ }^{+}$oxP $3^{+}$cells. Data shown are the representatives of two identical experiments $(\mathrm{N}=10)$. (B) Thy $1.1^{+}$FoxP3 $3^{+}$cells. Data shown are the representatives of two identical experiments $(\mathrm{N}=10)$. (C) Total numbers of cells. Data shown are the mean \pm S.E.M. of a representative of two identical experiments $(\mathrm{N}=10) .{ }^{* *}, p<0.001$; ns, no statistical difference, Student's unpaired $t$-test $)$.

Extended Data Table 1. Detailed CpG analysis of mouse FoxP3 DNA methylation. Seven CpG sites of FoxP3 regulators were analyzed. 
A
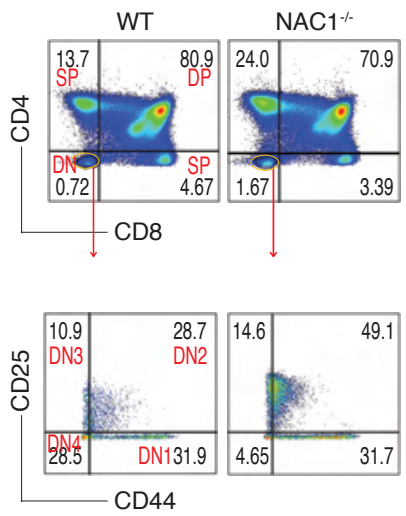

B
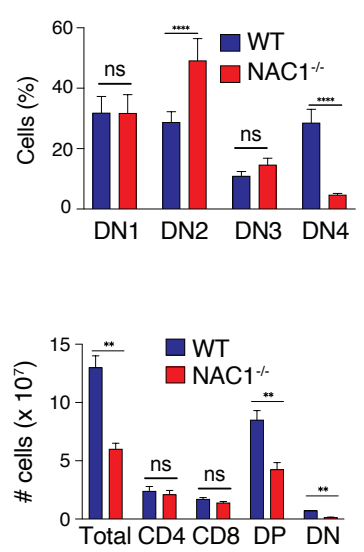

C

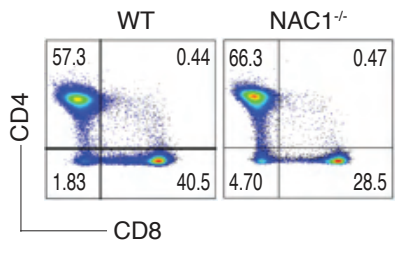

(Gated on $\mathrm{CD}^{+}$populations)

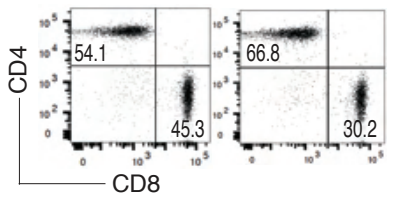

D
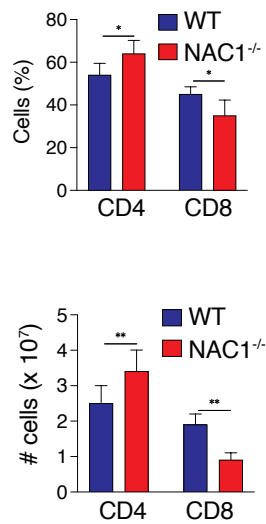

F
E
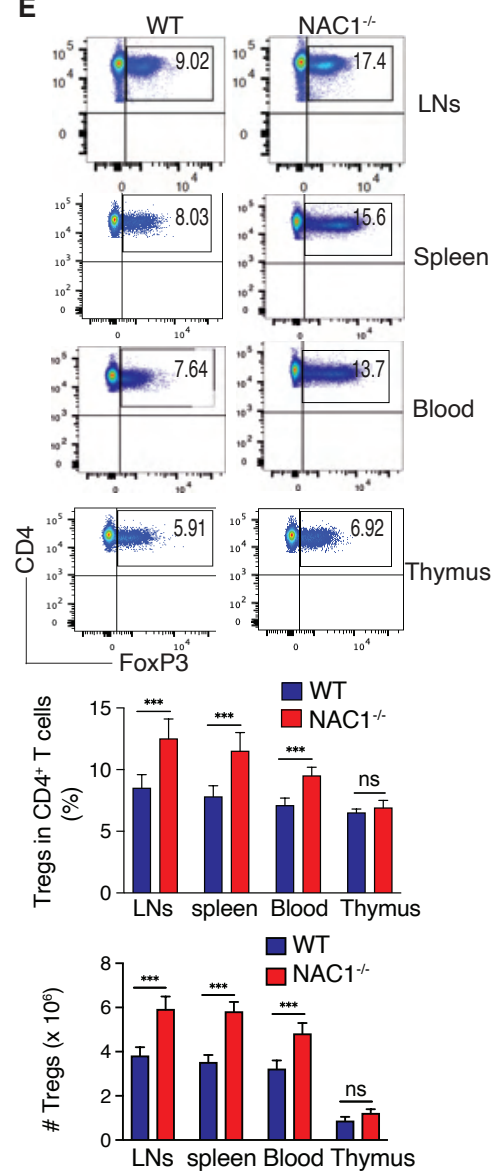
Figure 2
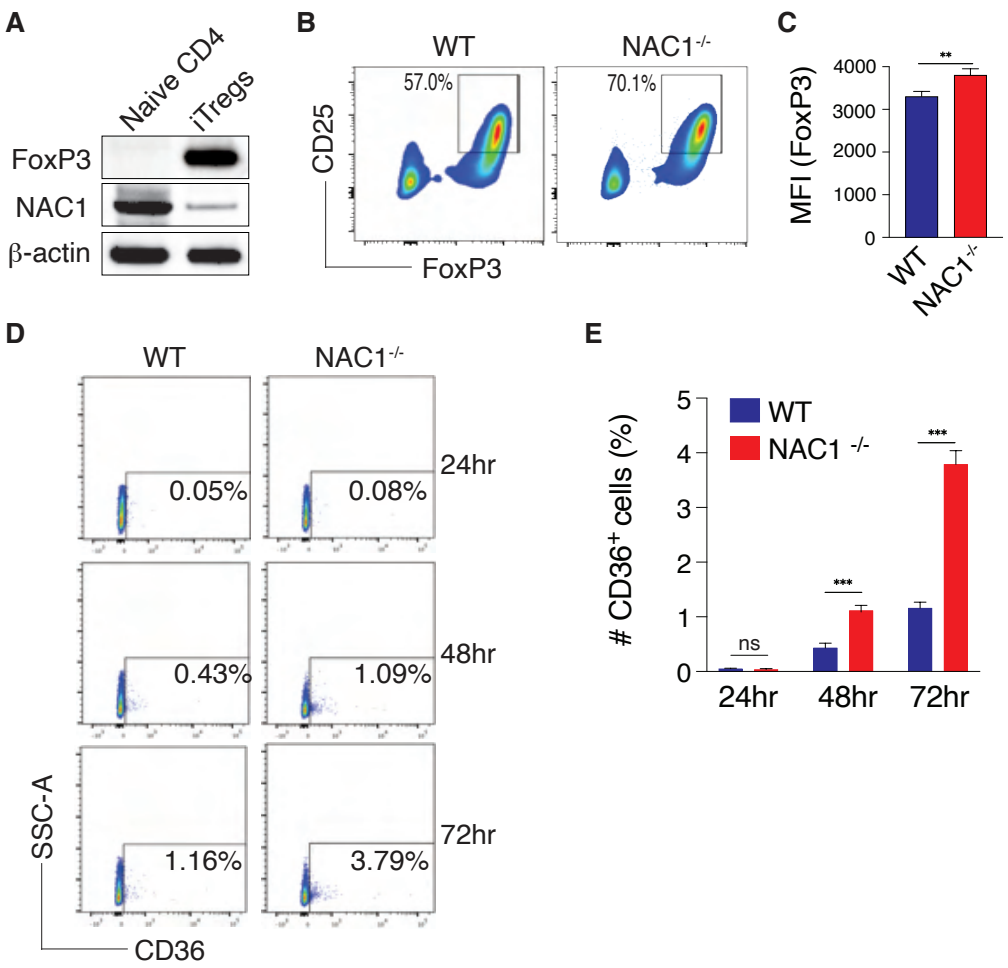

E

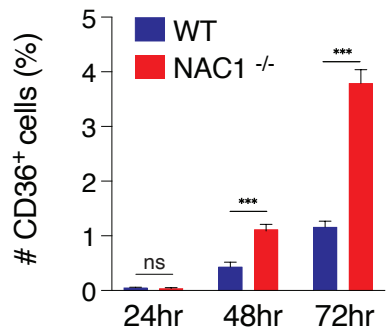




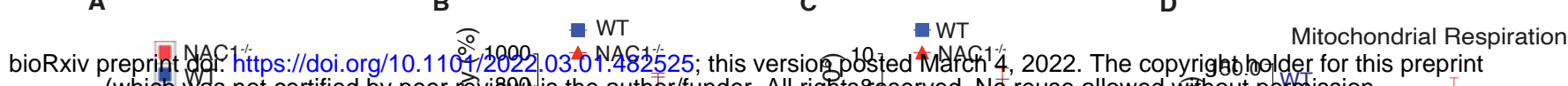

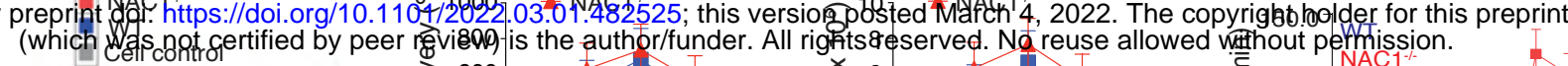
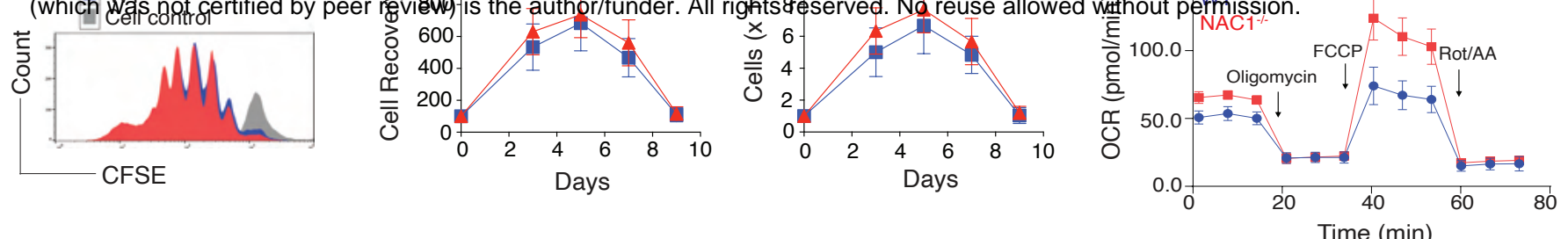

$\mathbf{F}$
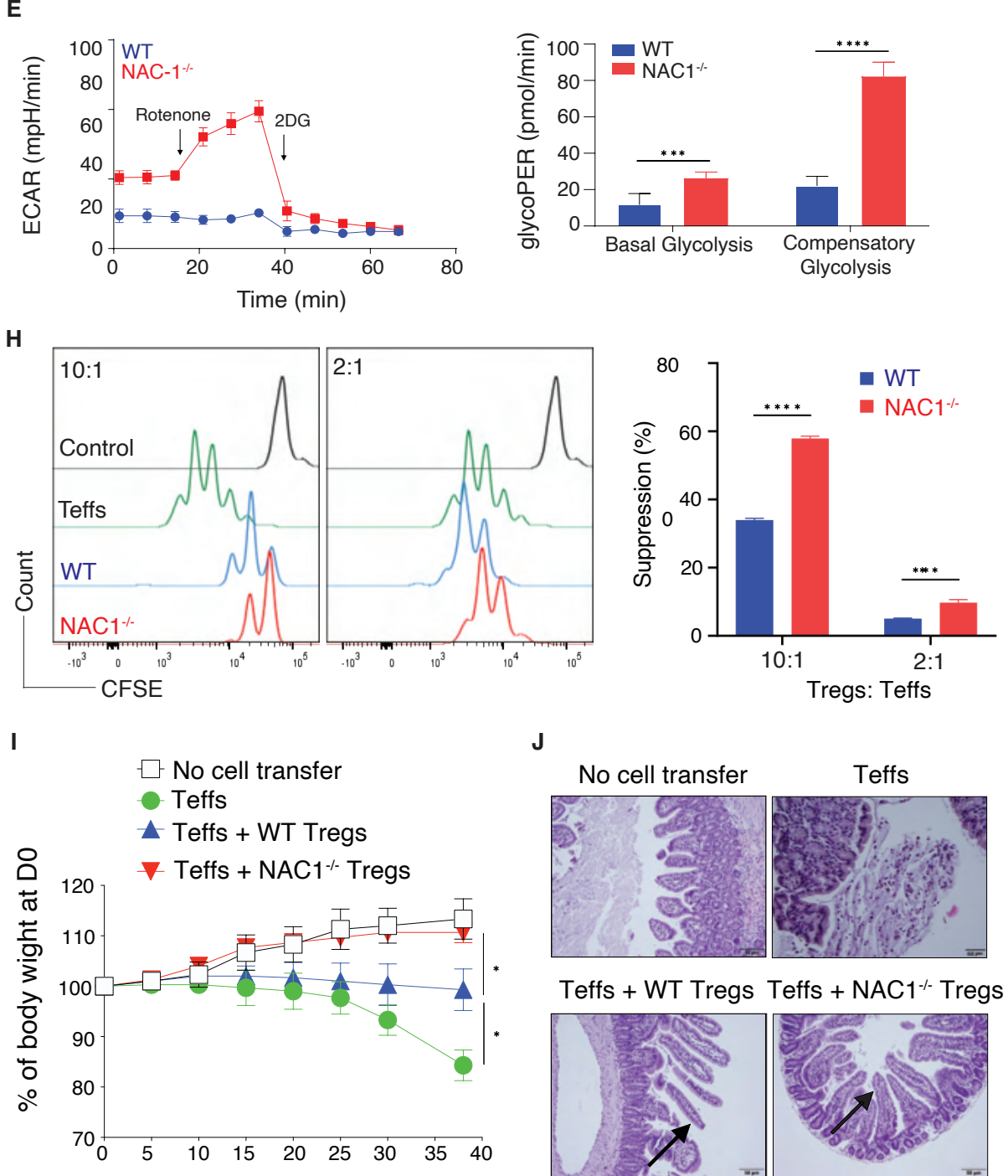

Days of cell transfer
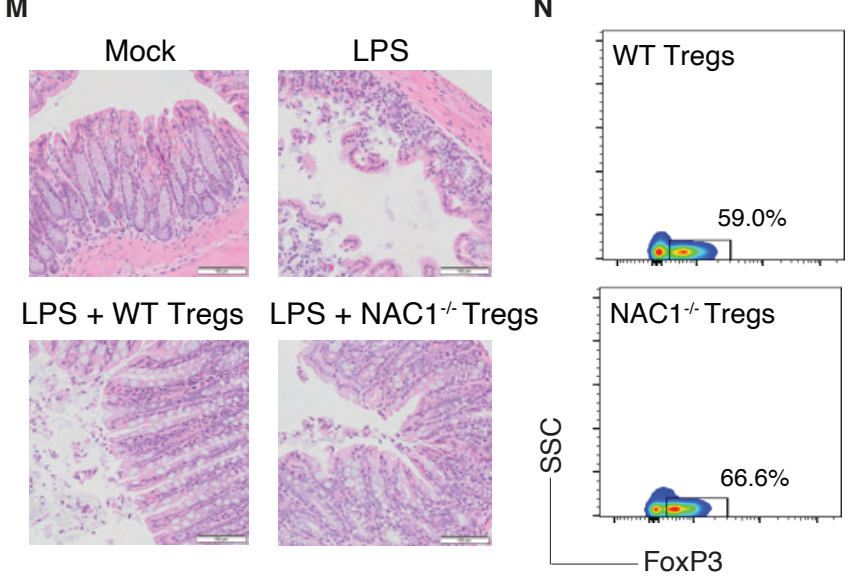

0

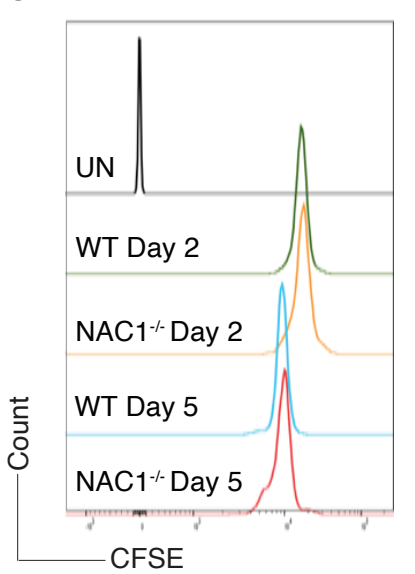

LPS + WT Tregs LPS + NAC1 ${ }^{-/}$Tregs

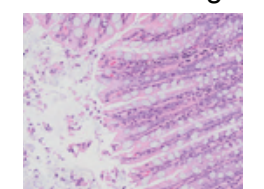

N

(4)
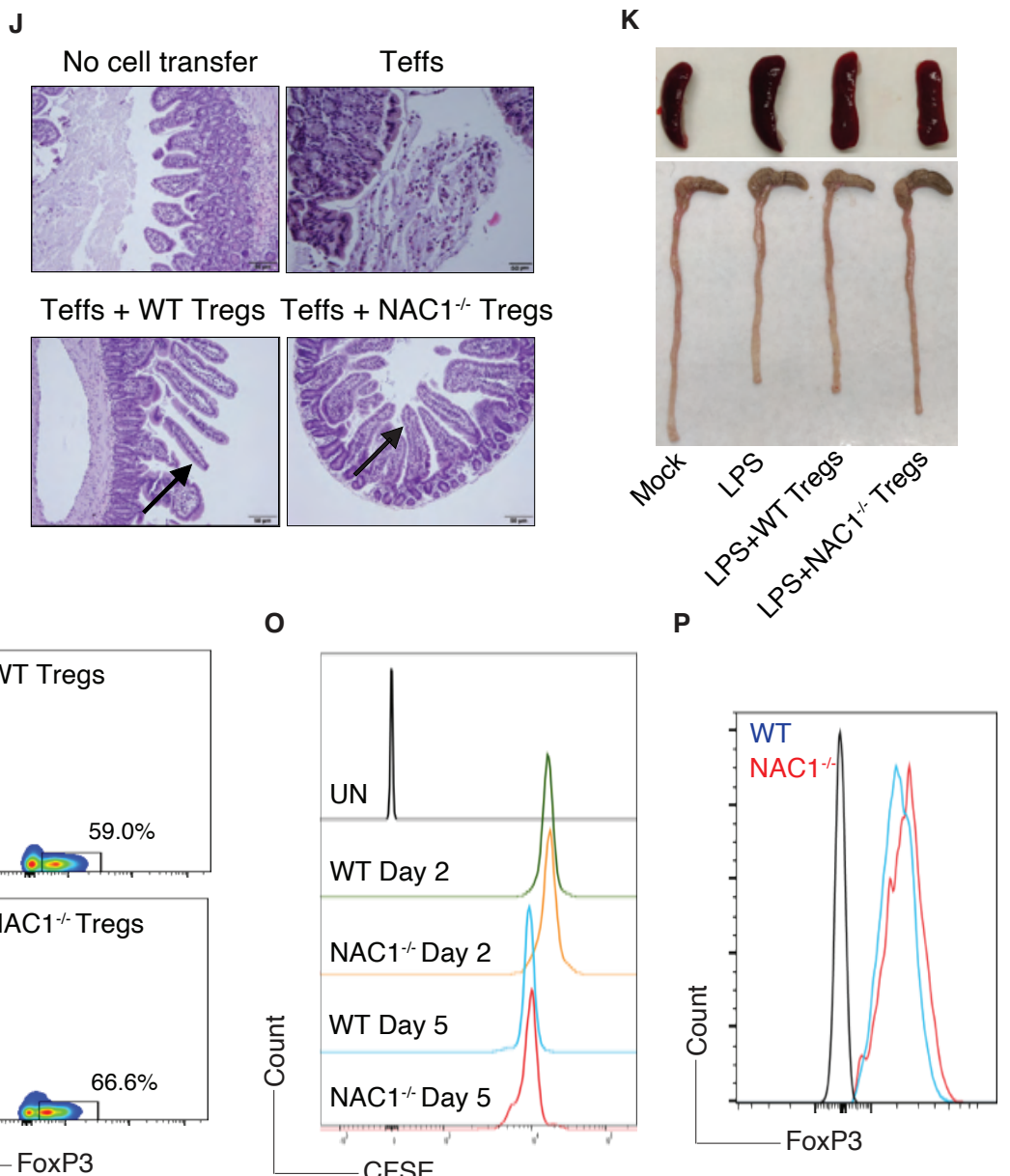
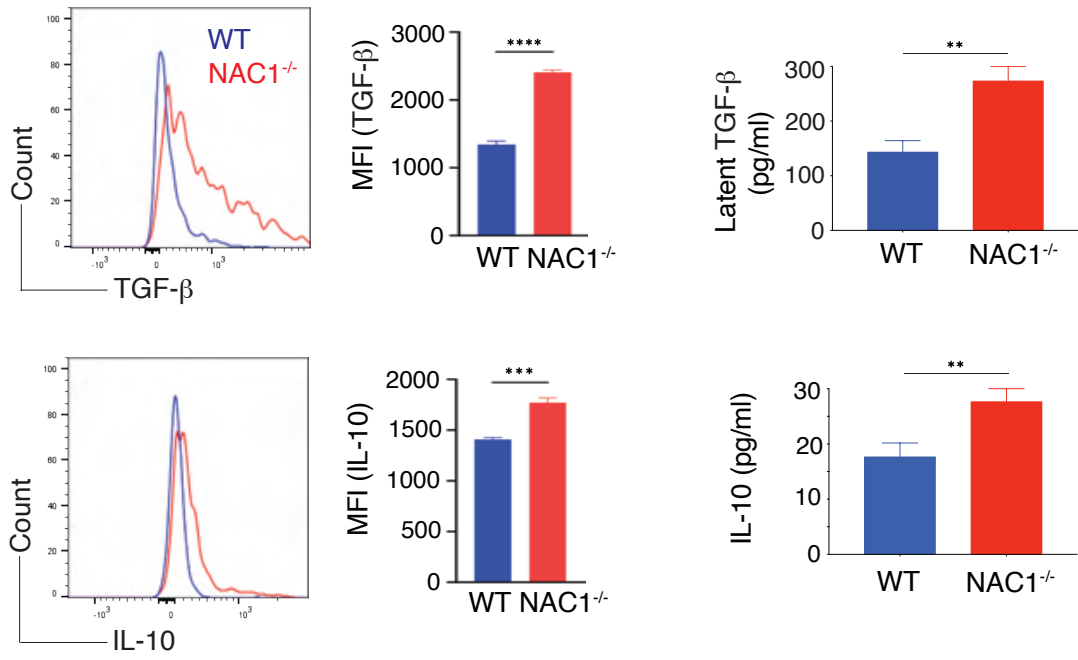

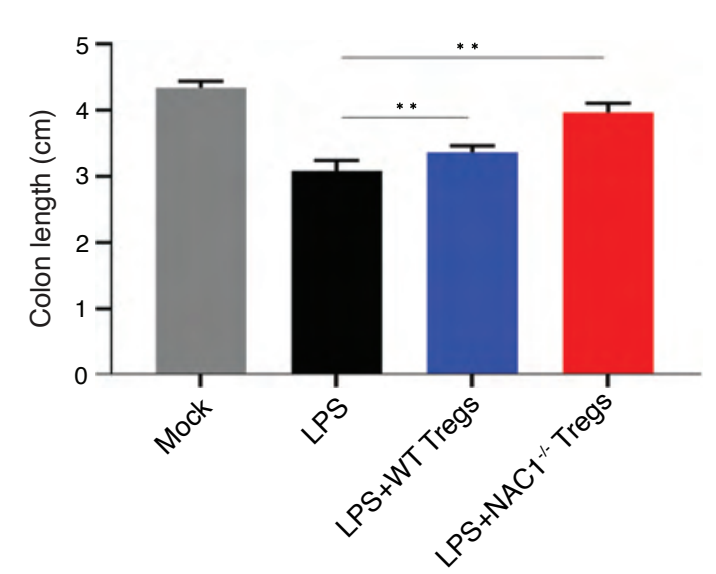

Q

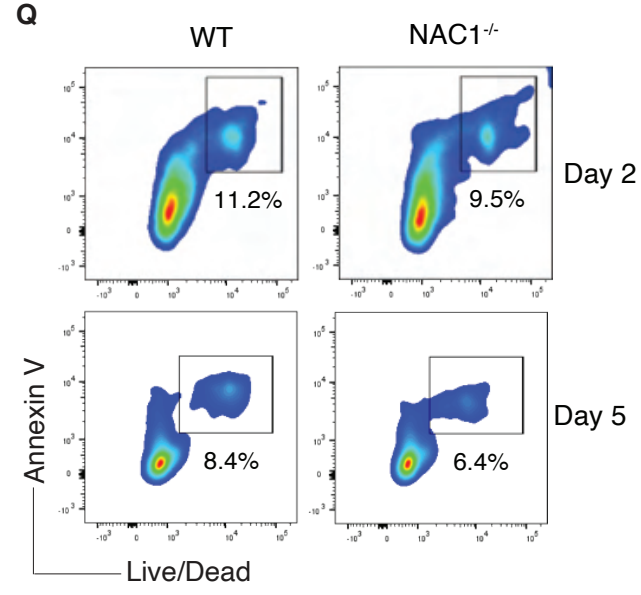


Figure 4

A

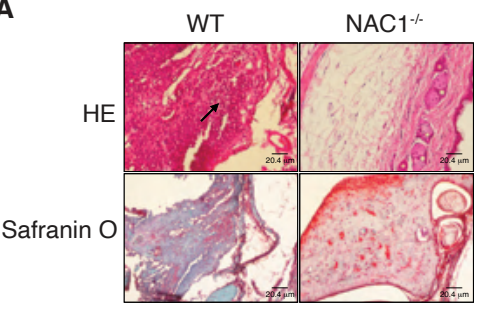

D

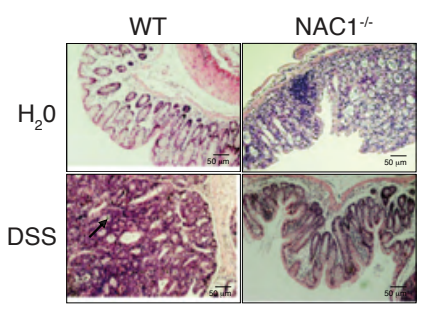

G

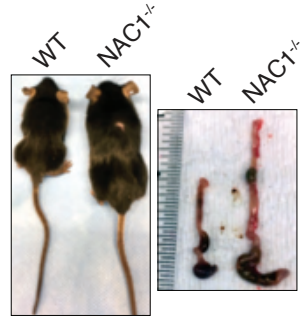

B

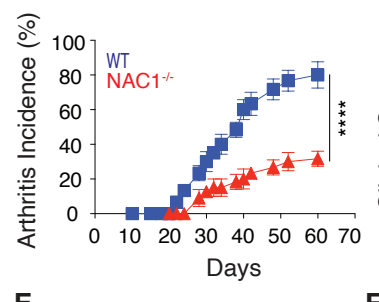

E
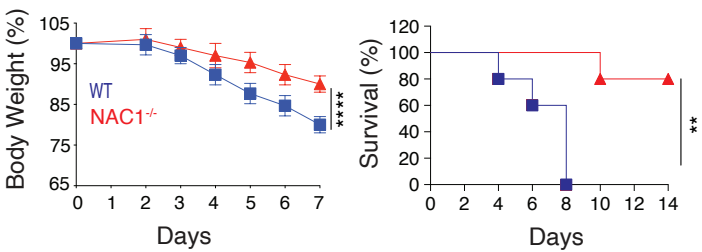

H
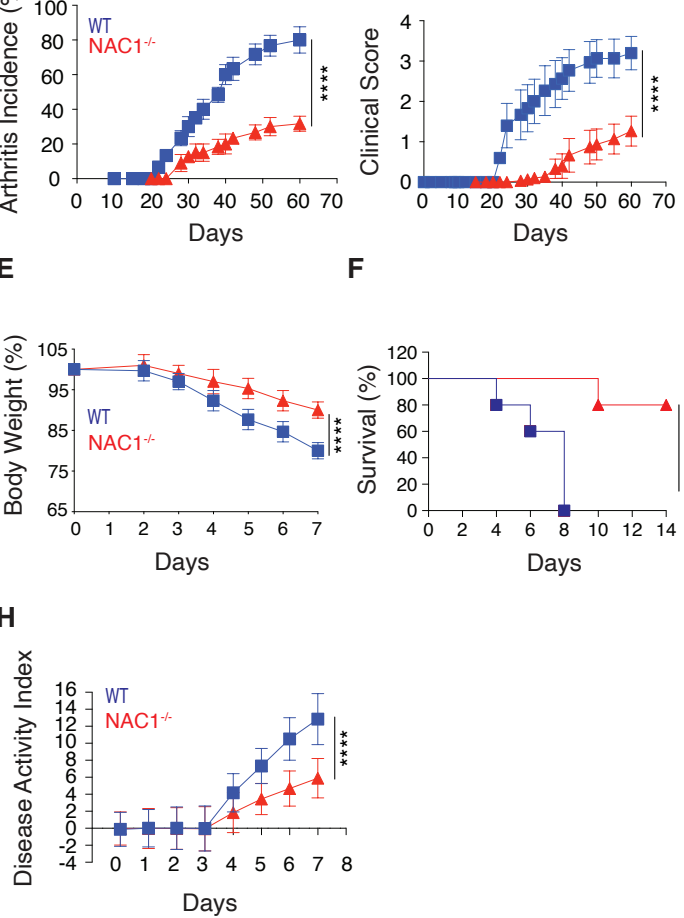

F 


\section{Figure 5}

A

Mouse FOXP3 Gene

Ensembl Gene ID: ENSMUSG00000039521

Ensembl Transcript ID: ENSMUST00000115740

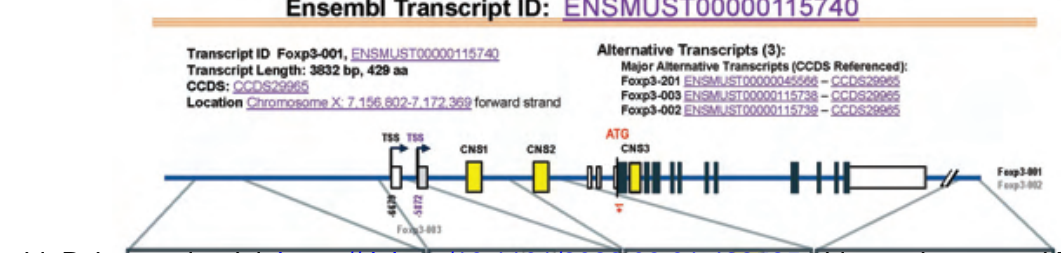

bioRxiv preprint doi: https://doi.o/g/10.1T01/2022/03.01.482525; this version posted March 4, 2022. The copyrigh (which was not certified by peer review) is the author/funder. All rights reserved. No reuse allowed witho

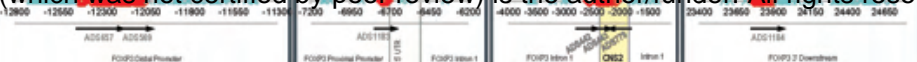

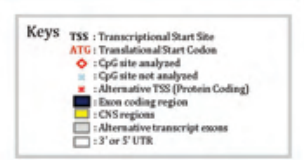

B

Mouse FOXP3 Gene

Ensembl Gene ID: ENSMUSG00000039521 Ensembl Transcript ID: ENSMUST00000115740

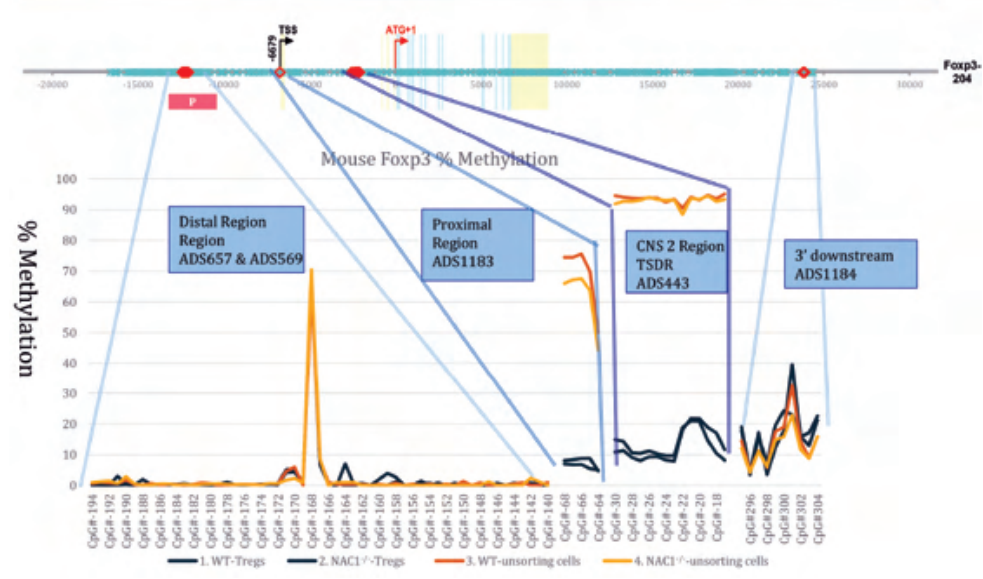

C
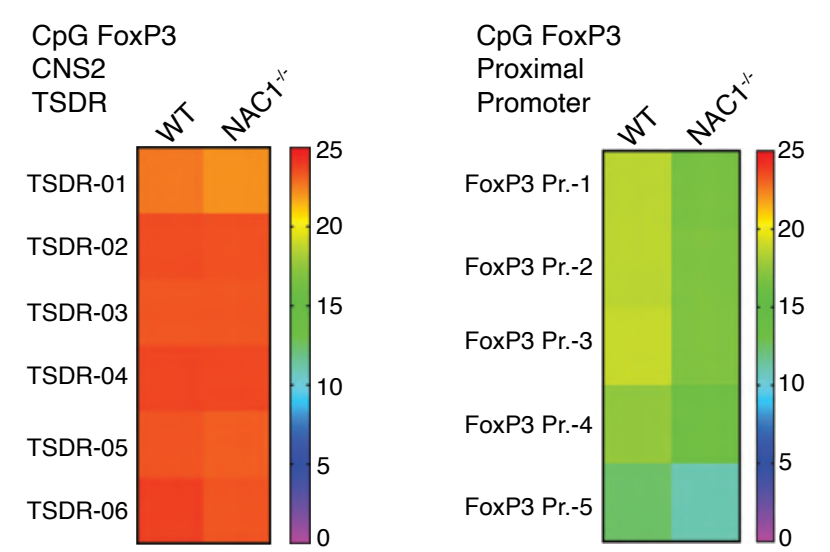

D
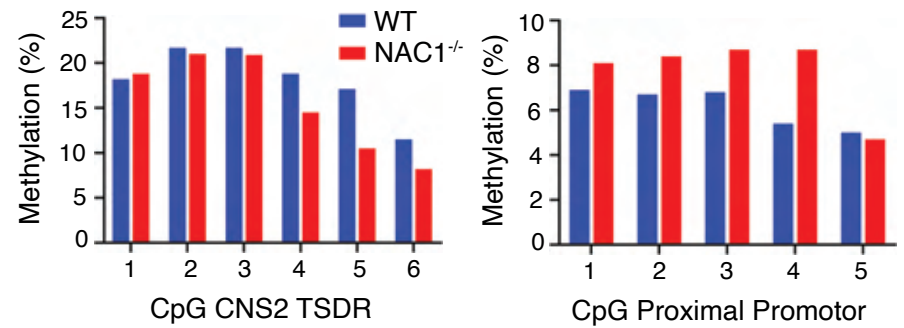
Figure 6

A

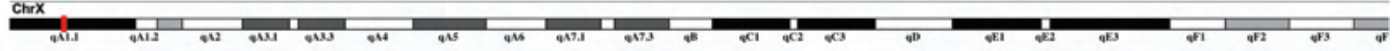

\begin{tabular}{|c|c|c|c|c|c|c|c|c|c|c|c|c|c|c|c|c|c|c|}
\hline sto & 1 & $7,580 \mathrm{Hot}$ & 1 & $7.592 \mathrm{ab}$ & 1 & $7.594 \times 6$ & 1 & $7.506 \mathrm{Bt}$ & 1 & 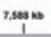 & 1 & $7,900 \mathrm{not}$ & 1 & $7,502 \times 2 \times$ & 1 & 7,594 no & 1 & r.sp: \\
\hline
\end{tabular}

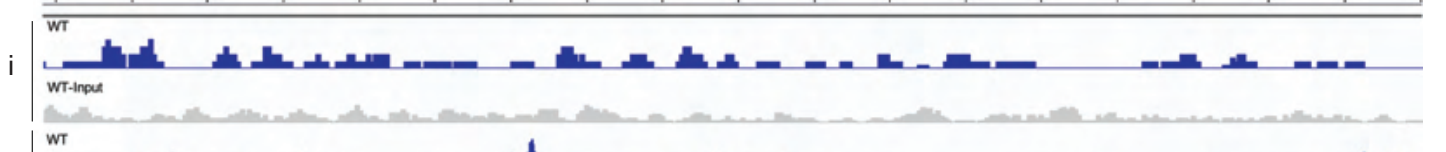

ii

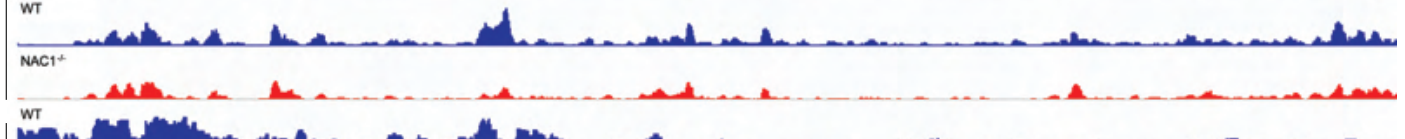

WT WT-Input

iii NAC1
Input

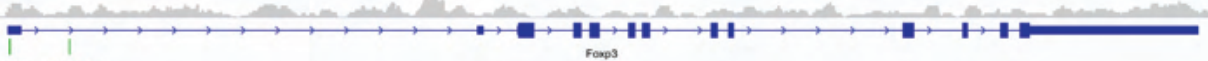

| ||||| ||||| ||| |||| |

B

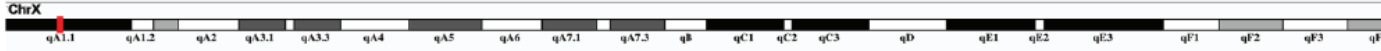

(1)

| |||||| |||||| ||| | ||| |

FoxP3

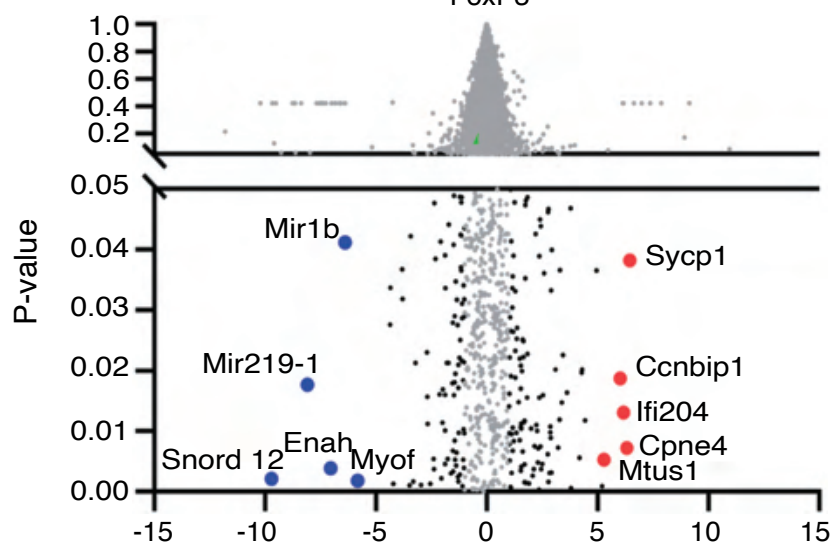


Figure 7

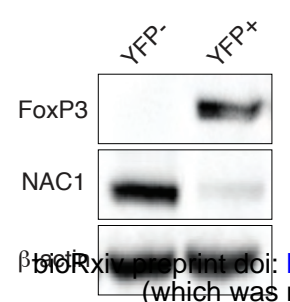

B

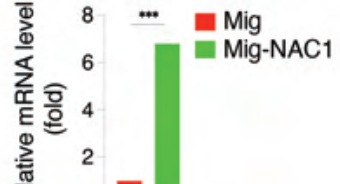

C

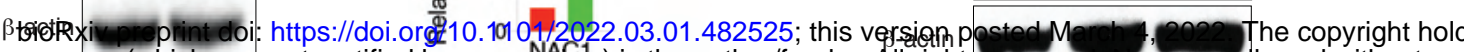
NAC1

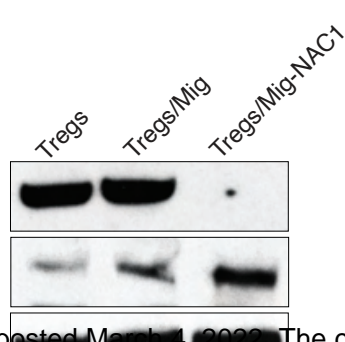

30

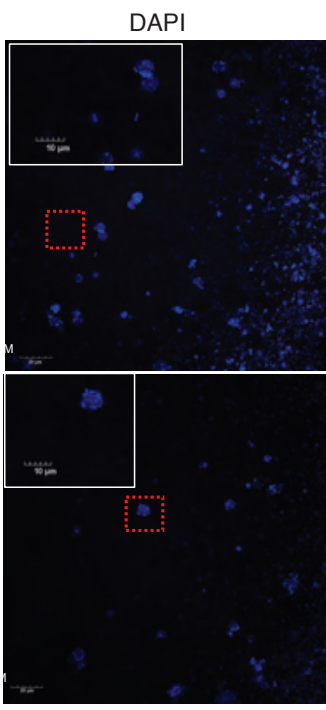

NAC1

FoxP3

Merge

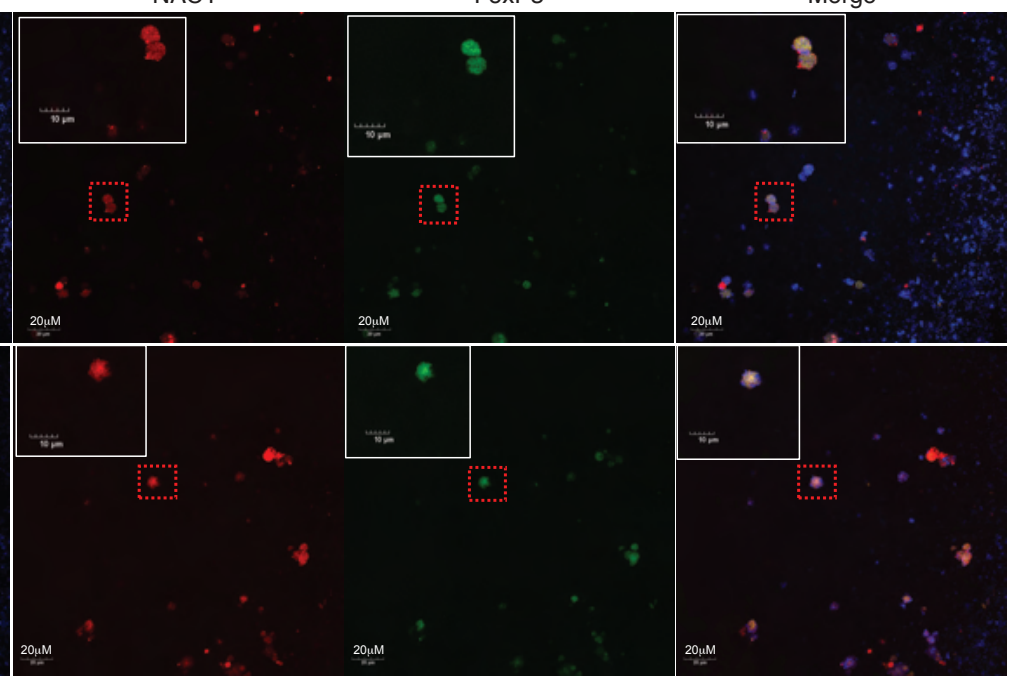

E

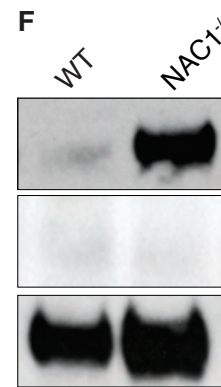

G

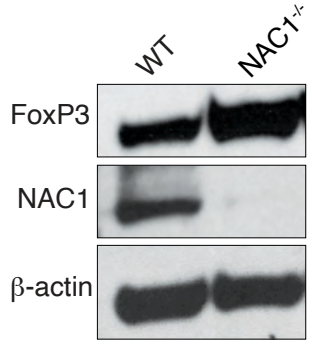

P. FoxP3

IB: pan-acetylation

IP: IgG

IB: pan-acetylation NAC1

IP: FoxP3 $\mid$ Input $\quad \beta$-actin

H

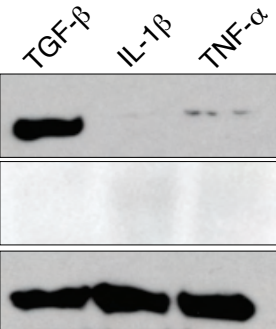

$-$

IP: IgG

IB: pan-acetylation $\beta$-actin

IP: FoxP3

IB: FoxP3 Input

J
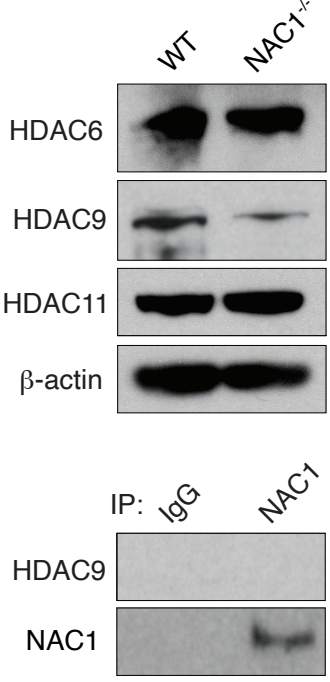
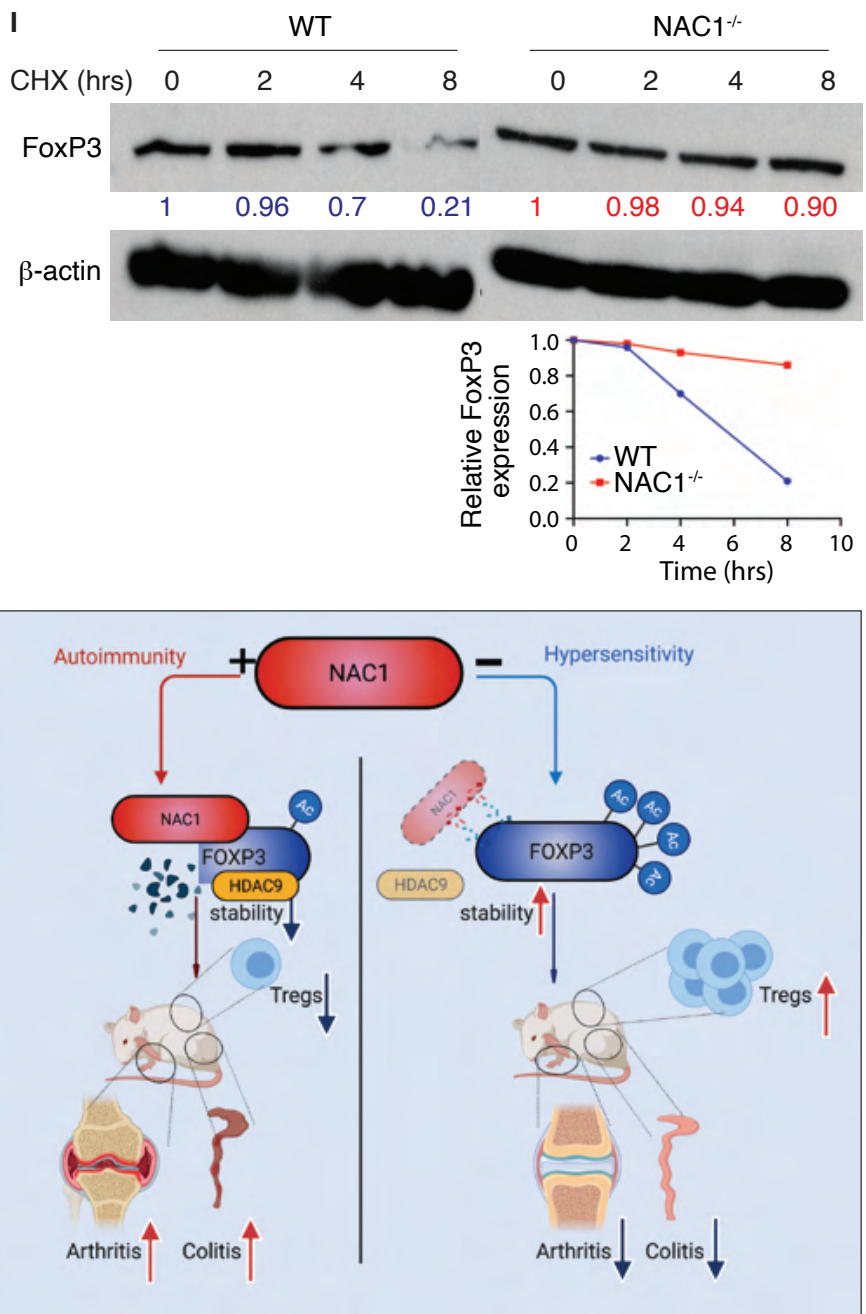


\section{Extended Figure 1}

A

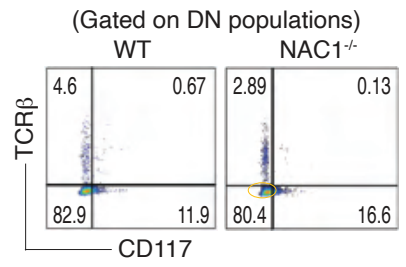

B

(Gated on DN4 populations)
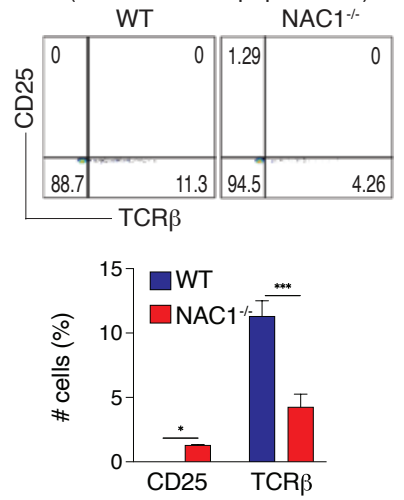


\section{Extended Figure 2}

A

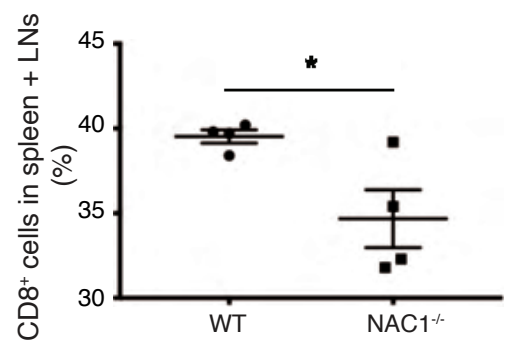

C

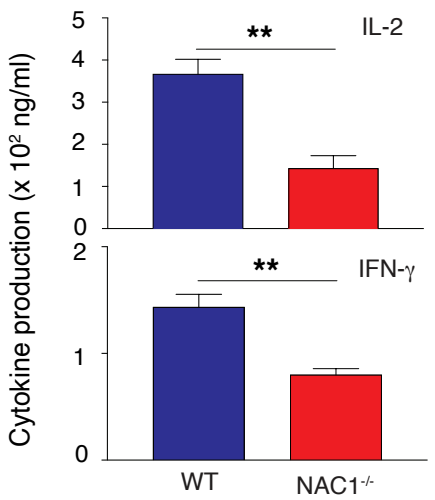

B

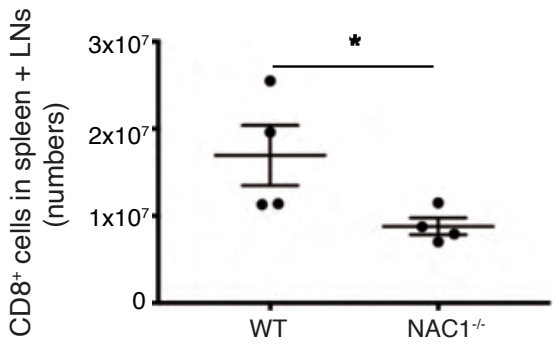

D

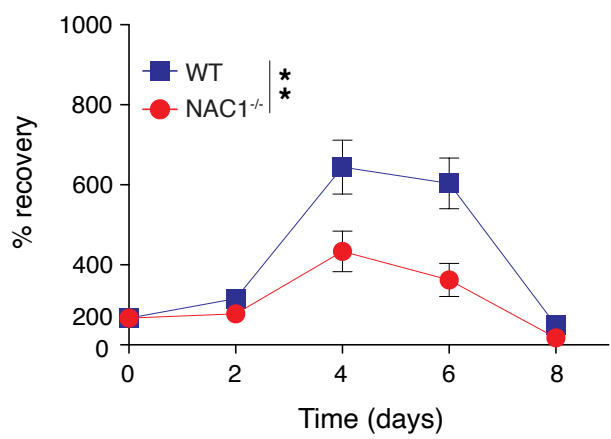




\section{Extended Figure 3}

A

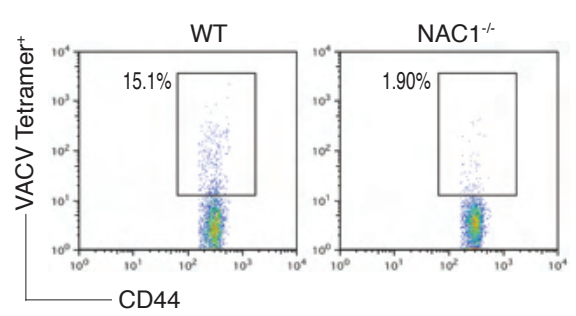

B

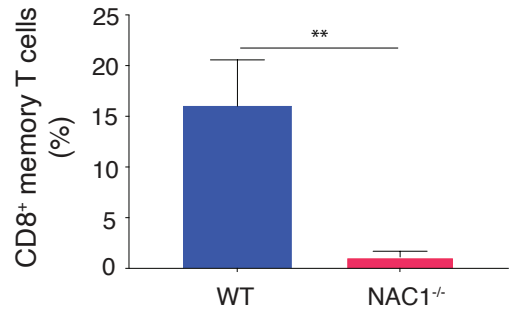




\section{Extended Figure 4}

A
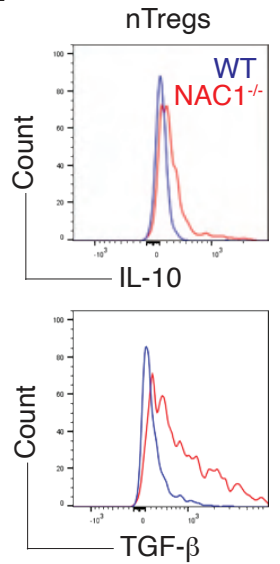

B
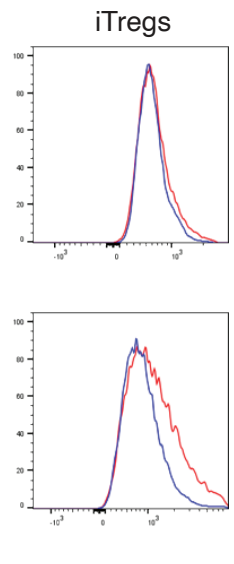
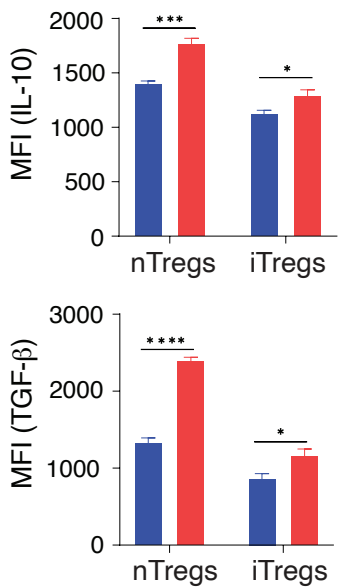


\section{Extended Figure 5}

A

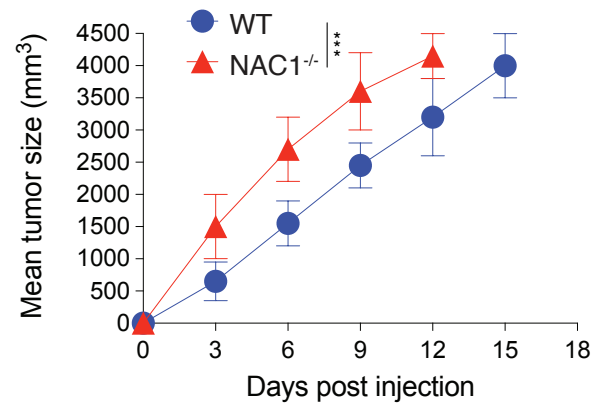

B

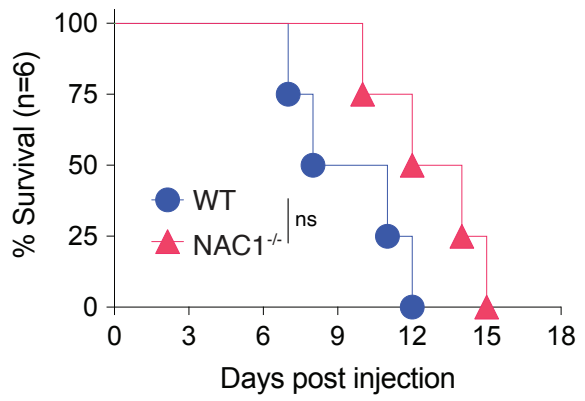




\section{Extended Figure 6}

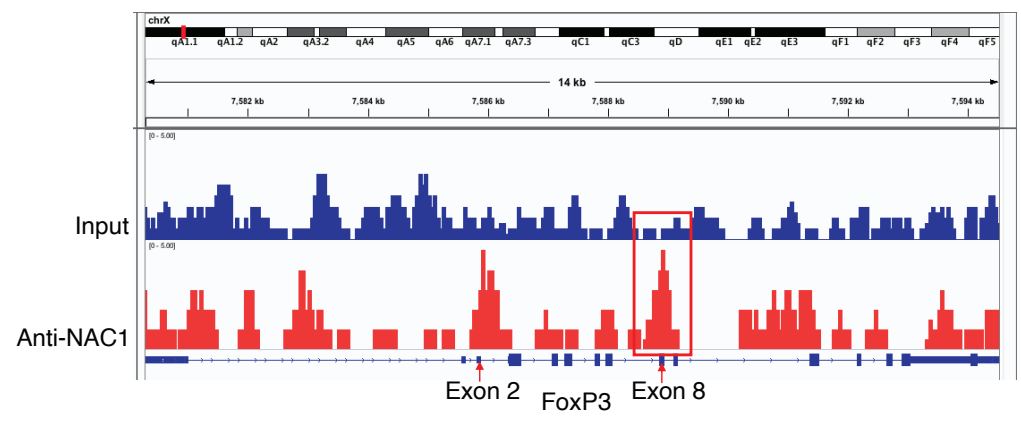




\section{Extended Figure 7}

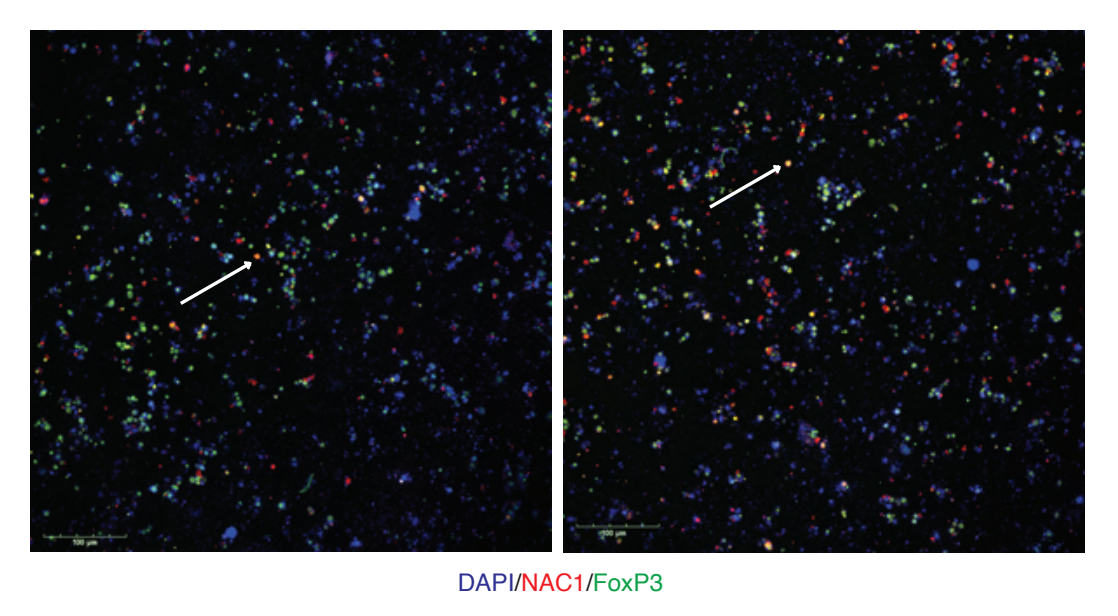

DAPI/NAC1/FoxP3
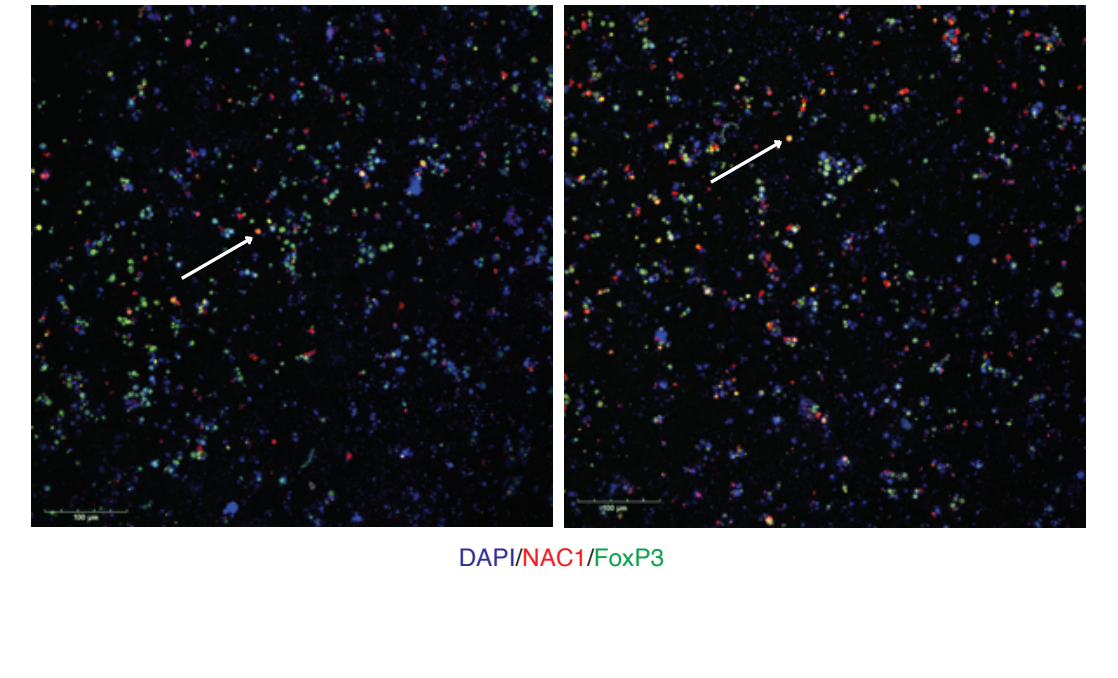

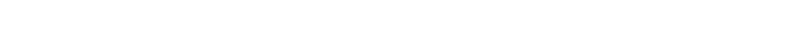
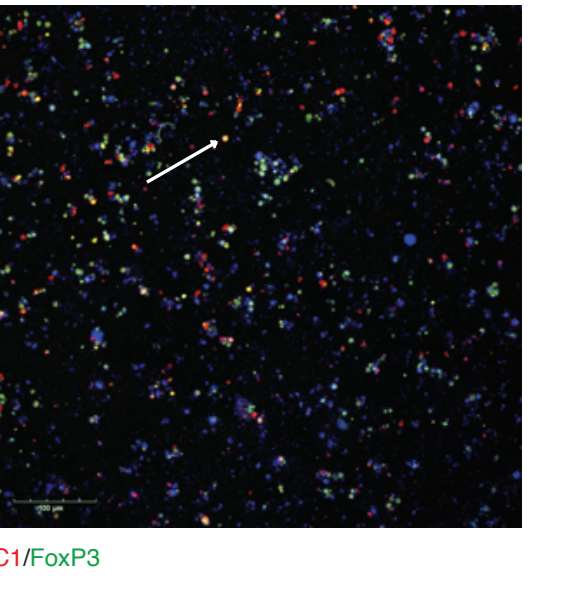


\section{Extended Figure 8}

A

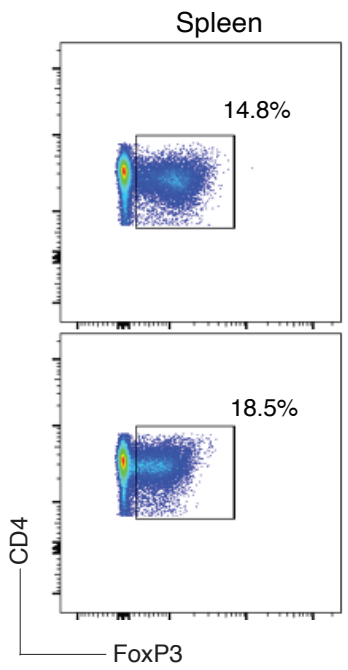

LNs

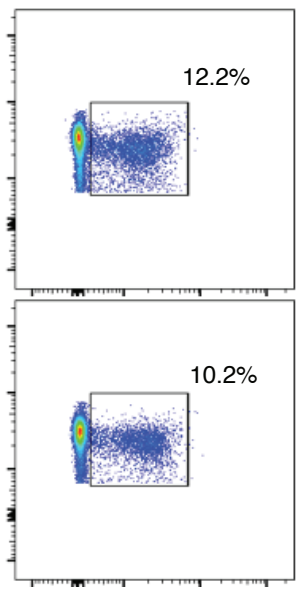

LNs

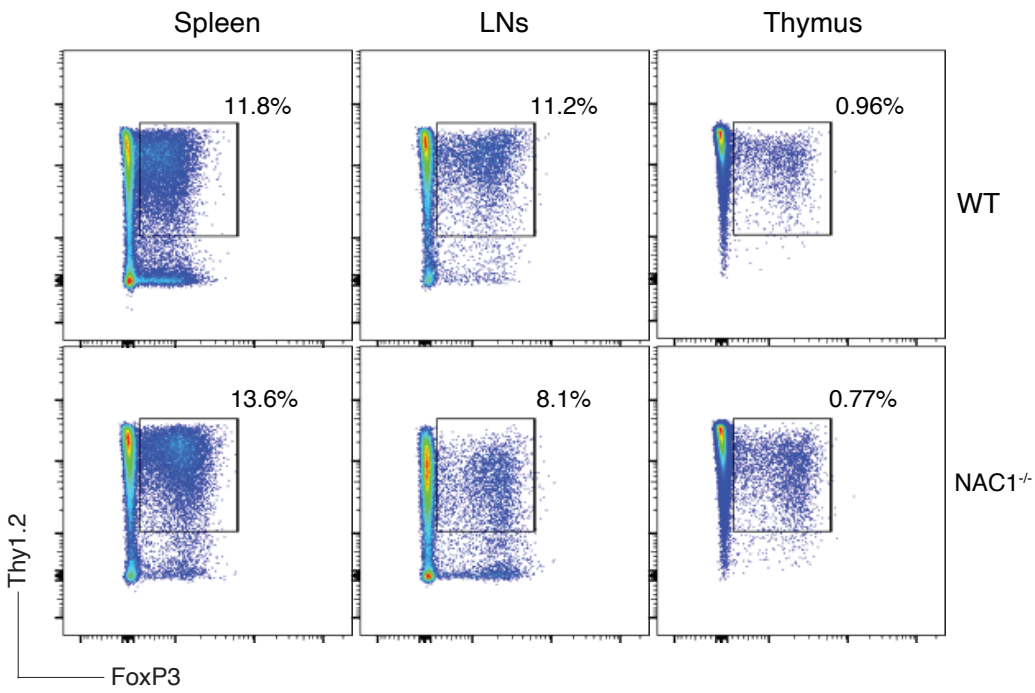

C

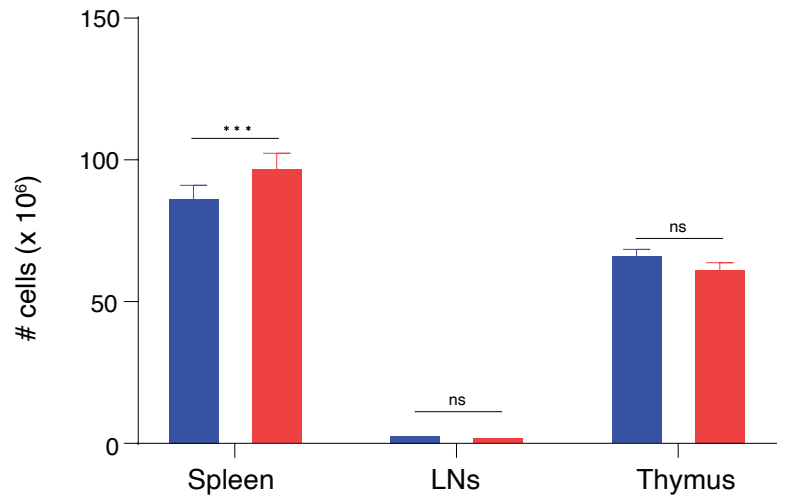




\section{Extended Table 1 Detailed CpG analysis of mouse FoxP3 DNA methylation}

\begin{tabular}{|c|c|c|c|c|c|c|}
\hline & \multicolumn{5}{|c|}{ Mouse FoxP3 DNA Methylation } \\
\hline Gene & Assay ID & Assay Location & From ATG & From TSS & Coordinates & \# of CpG \\
\hline Foxp3 & ADS657 & 5-Upstream & -12434 to -12224 & -5755 to -5545 & ChrX:7573921-7574131 & 25 \\
\hline Foxp3 & ADS1183 & 5-Upstream & -6750 to -6714 & -71 to -35 & ChrX: $7579605-7579641$ & 5 \\
\hline Foxp3 & ADS569 & 5-Upstream & -12210 to -12059 & -5531 to -5380 & ChrX: $7574145-7574296$ & 30 \\
\hline Foxp3 & ADS443 & Intron 1 & -2405 to -2353 & 4275 to 4327 & ChrX:7583950-7584002 & 3 \\
\hline Foxp3 & ADS442 & Intron 1 & -2555 to -2533 & 4125 to 4147 & ChrX: $7583800-7583822$ & 2 \\
\hline Foxp3 & ADS779 & Intron 1 & -2145 to -2075 & 4535 to 4605 & ChrX:7584210 -7584280 & 2 \\
\hline Foxp3 & ADS1184 & 3-Downstream & 23773 to 23905 & 30452 to 30584 & ChrX:7610127-7610259 & 10 \\
\hline
\end{tabular}

\begin{tabular}{|c|c|c|c|c|c|c|}
\hline Assay ID & Assay Location & From ATG & From Tss & $\mathrm{NCB137} / \mathrm{mm} 9$ & $\mathrm{GRCm} 38 / \mathrm{mm} 10$ & $\#$ of CpG \\
\hline ADS657-FS1 & Distal Promoter & -12434 to -12401 & -5755 to -5722 & Chrx:7151047-7151080 & ChrX:7573921-7573954 & 6 \\
\hline ADS657-FS2 & Distal Promoter & -12359 to -12353 & -5680 to -5674 & Chrx: $7151122-7151128$ & Chrx: $7573996-7574002$ & 2 \\
\hline ADS657-FS3 & Distal Promoter & -12335 to -12253 & -5656 to -5574 & Chrx: $7151146-7151228$ & ChrX: $7574020-7574102$ & 15 \\
\hline ADS657-FS4 & Distal Promoter & -12231 to -12225 & -5551 to -5545 & Chrix:7151251-7151257 & ChrX: $7574125-7574131$ & 2 \\
\hline ADS569-FS1 & Distal Promoter & -12210 to -12136 & -5531 to -5457 & Chrx:7151271-7151345 & ChrX: $7574145-7574219$ & 15 \\
\hline AD5569-F52 & Distal Promoter & -12118 to -12059 & -5439 to -5380 & Chrx: 7151363-7151422 & ChrX: $7574237-7574296$ & 15 \\
\hline ADS1183-FS & Proximal Promoter & -6750 to -6714 & -71 to -35 & Chrx: $7156731-7156767$ & ChrX: $7579605-7579641$ & 5 \\
\hline ADS442-FS & Intron 1 & -2555 to -2533 & +4125 to +4147 & ChrX:7160926-7160948 & ChrX: $7583800-7583822$ & 2 \\
\hline ADS443-FS & Intron 1 & -2405 to -2353 & +4275 to +4327 & Chrx: 7161076-7161128 & ChrX: $7583950-7584002$ & 3 \\
\hline ADS443-FS2 & Intron 1 & -2319 to -2287 & +4361 to +4393 & Chrx:7161162-7161194 & ChrX: $7584036-7584068$ & 3 \\
\hline ADSS68-FS1 & Intron 1 & -2369 to -2287 & +4311 to +4393 & Chrx:7161112-7161194 & Chrx: $7583986-7584068$ & 5 \\
\hline ADS568-FS2 & Intron 1 & -2238 to -2207 & +4442 to +4473 & Chrx: 7161243-7161274 & ChrX: $7584117-7584148$ & 4 \\
\hline ADS779-RS1 & Intron 1 & -2075 to -2145 & +4605 to +4535 & Chrx:7161406-7161336 & Chrx: $7584280-7584210$ & 2 \\
\hline ADS1184-FS1 & 3' downstream & +23773 to +23784 & +30452 to +30463 & Chrx: 7187253-7187264 & ChrX: $7610127-7610138$ & 2 \\
\hline ADS1184-FS2 & $3^{\prime}$ downstream & +23802 to +23840 & +30481 to +30519 & Chrx: $7187282-7187320$ & ChrX:7610156-7610194 & 5 \\
\hline ADS1184-FS3 & 3' downstream & +23863 to +23905 & +30542 to +30584 & Chrix:7187343-7187385 & Chrx:7610217-7610259 & 3 \\
\hline
\end{tabular}




\section{Extended Methods}

\section{Reagents}

H-2K ${ }^{\mathrm{b}}$ VACV B8R (TSYKFESV) Tetramer (\#TB-M538-1, MBL), anti-mouse CD36 antibody (clone HM36, BioLegend), anti-human/mouse/rat NAC1 antibody (clone SWN-3, BioLegend), anti-human FoxP3 antibody (clone 206D, BioLegend), and L-(+)-Lactic acid (\#ICN19022805, MP Biomedicals).

\section{Viral infection}

VACV infection was performed by an intraperitoneal injection of viruses $\left(2 \times 10^{6} \mathrm{PFU} / \mathrm{mouse}\right)$ as described (40).

\section{Murine Melanoma Model}

WT or NAC1 $1^{-/-}$Tregs $\left(1 \times 10^{5}\right)$ were injected s.c.in the flank region of the recipient mice inoculated with $1 \times 10^{6}$ B16 tumor cells. Tumor sizes were measured by a caliper and tumor volumes were calculated as: $\mathrm{V}=$ long diameter $\times$ short diameter $^{2} \times 0.52(41)$.

\section{LPS-induced colitis}

To induce colitis, B6.Thy1.1 Tg mice were i.p. injected with $20 \mu \mathrm{g} / \mathrm{kg}$ LPS. In the following day, $3 \times 10^{6} \mathrm{WT}$ or $\mathrm{NAC1}^{-/-}$Tregs were i.v. transferred into LPS-challenged mice via the tail vein. Seven days later, mice were sacrificed and the colons and spleens of the mice were dissociated. The length of colon was measured, and the colons were processed for H\&E staining and flow cytometric analysis. 


\section{Generation of bone marrow chimera}

To prepare B6. Thy $1.1^{+} \mathrm{Tg}$ recipient mice for irradiation, drinking water was removed $12 \mathrm{hrs}$ prior to irradiation. The mice were then X-ray irradiated (1000 rad) with a RS200 X-ray irradiator (Rad Source Technologies Inc. GA, USA). The bone marrow cells were harvested from femur of C57BL/6 Thy $1.2^{+} \mathrm{WT}$ and $\mathrm{NAC1}^{-/-}$mice, using standard procedures. Red blood cells (RBCs) were lysed, and $\mathrm{CD}^{+}$cells and $\mathrm{CD}^{+}$cells were depleted by the negative selection using biotin conjugated anti-CD4 and anti-CD8 antibodies and streptavidin nanobeads. $\mathrm{CD}^{+}$and $\mathrm{CD} 8^{+}-$ depletions were analyzed by flow cytometry. Ten millions of CD4/CD8-depleted WT and NAC1-

/- bone marrow cells were i.v. injected into the irradiated B6.Thy $1.1^{+}$recipient mice. Sulfatrim (sulfamethoxazole and trimethoprim oral suspension)-containing drinking water $(5 \mathrm{ml} / 200 \mathrm{ml})$ was given to the irradiated animals for 2 weeks. After 6 weeks, the spleen, LNs and thymus were isolated, and cells were analyzed by flow cytometry to evaluate the development of Tregs. 


\section{Author contributions}

J.Y. and J.S. designed the experiments, analyzed the data, and wrote this paper. Y.R., A.K., X.X., JK.D., H.P., L.W., Y.Z. C.J., Y.C., and L.Z. performed the experiments. D.F., RC.A., P.dF. and J. W. provided reagents or NAC1 $1^{-/}$mice. X.X., JK.D., H.P., Y.Z., C.J., L.Z., X.L and Y.C. analyzed the data.

\section{Acknowledgments}

This work was supported by National Cancer Institute Grant R01CA221867 to JM. Yang and J.S., and National Institute of Health Grant R01AI121180 and R21AI128325, the American Diabetes Association (1-16-IBS-281), and Department of Defense Grant LC210150 to J.S.

\section{Guarantor's statement}

J.Y. and J.S. are the guarantors of this work and, as such, had full access to all the data in the study and takes responsibility for the integrity of the data and the accuracy of the data analysis.

\section{Conflict of interest}

The authors have declared that no conflict of interest exists. 


\section{Legends to Extended Data}

\section{Extended Data Figure 1. NAC1 ${ }^{-/-}$mice have a decreased percentage of TCRV $\beta$ cells in DN4} stage. The thymocytes from $\mathrm{WT}$ or $\mathrm{NAC1}^{-/-}$mice were analyzed by flow cytometry and calculated for numbers or percentages. (A) CD117 and TCR V $\beta$. The DN populations were analyzed for CD117 and TCRV $\beta$. Data shown are the representative of three identical experiments. (B) TCRV $\beta$ and CD25. The DN4 populations were analyzed for TCR V $\beta$ and CD25. Data are the representative of three identical experiments $(\mathrm{N}=5) . *, p<0.05, * *, p<0.01, * * *, p<0.001$, Student's unpaired $t$ test.

Extended Data Figure 2. $\mathrm{NAC1}^{-/-} \mathrm{CD8}^{+} \mathrm{T}$ cells are defective in cytokine production and survival. (A-B) Percentages (A) and numbers (B) of $\mathrm{CD}^{+} \mathrm{T}$ cells from the pooled LNs and spleen of WT or $\mathrm{NAC1}^{-/-}$mice. Data shown are the representative of three identical experiments. The values represent mean \pm S.D. $(\mathrm{N}=3) .{ }^{*}, p<0.05$, Student's unpaired $t$-test. (C-D) Purified $\mathrm{CD}^{+} \mathrm{T}$ cells from the pooled LNs and spleen of $\mathrm{WT}$ or $\mathrm{NAC1}^{-/-}$mice were stimulated with antiCD3 plus CD28 antibodies. (C) Cytokine production. ${ }^{* *} p<0.01$, Student's unpaired $t$-test. The values represent the mean \pm S.D. $(\mathrm{N}=3)$. (D) Cell recovery on various days. The numbers of $\mathrm{T}$ cells present on day 0 were assigned a value of $100 \%$, and numbers surviving on various days were used to calculate the percentage recovery relative to day 0. Data shown are the mean \pm S.E.M. of percentage change of a representative of three identical experiments $(\mathrm{N}=3){ }^{* *}, p<0.01$, Nested $t$-test).

Extended Data Figure 3. Memory $\mathrm{CD8}^{+} \mathrm{T}$ cell development is altered in $\mathrm{NAC1}^{-/-}$mice. WT or $\mathrm{NAC1}^{-/-}$mice were challenged with VACV (i.p.) for 35 days, then the pooled LNs and spleen were 
analyzed by flow cytometry. (A) CD44 and VACV tetramer staining, gating on $\mathrm{CD}^{+} \mathrm{CD} 44^{+}$ population. (B) Quantification of percentage of memory $\mathrm{CD} 8^{+} \mathrm{T}$ cell populations. The results shown are the mean \pm S.E.M. of three identical experiments $(\mathrm{N}=5)$. ${ }^{* *} P<0.01$, Student's unpaired $t$-test.

\section{Extended Data Figure 4. Both $\mathrm{NAC1}^{-/-}$iTregs and nTregs produce more suppressive} cytokines than WT iTregs and nTregs. WT or $\mathrm{NACl}^{-/-}$iTregs and nTregs were examined productions of suppressive cytokines (IL-10 and TGF- $\beta$ ) by intracellular staining and flow cytometric analysis. (A) Productions of IL-10 and TGF- $\beta$. (B) MFI of IL-10 and TGF- $\beta$. Data shown are the representative of three identical experiments. $* P<0.05, * * *, P<0.0001, * * *$, $P<0.00001$, Student's unpaired $t$-test.

Extended Data Figure 5. NAC1 ${ }^{-/-}$Tregs show enhanced suppressive function. WT or NAC1 ${ }^{-/}$ Tregs $\left(1 \times 10^{5}\right)$ were injected s.c.in the flank region of the recipient mice with $1 \times 10^{6} \mathrm{~B} 16$ tumor cells on various days. (A) Tumor growth. Data shown are the mean \pm S.E.M. of tumor sizes of a representative of three identical experiments $(\mathrm{N}=6) . * * *, P<0.0001$, simple linear regression. (B) Survival curves. Data shown are the representative of three identical experiments $(\mathrm{N}=6)$. ns, $P>0.05$, Log-rank (Mantel-Cox) test.

\section{Extended Data Figure 6. FoxP3 elements regulated by NAC1 are located between Exon 2}

and Exon 8. ChIP-seq analysis of naive $\mathrm{CD} 4^{+} \mathrm{CD} 25^{+}$Tregs from the pooled LNs and spleen of WT mice. NAC1-enriched islands are shown. Representative genomic regions (Exon 2 and Exon 
8) show NAC1 enrichment. Normalized ChIP-seq reads (bigWig) and enriched islands (bed) are shown. Results shown are the representative of three identical experiments

\author{
Extended Data Figure 7. Co-localization of NAC1 and FoxP3 in the nuclei of Tregs. \\ Immunofluorescent staining of DAPI, NAC1 and FoxP3 in Tregs generated in vitro. Arrows \\ indicate overlays with DAPI, NAC1 and FoxP3. Data shown are the representatives of three \\ identical experiments.
}

Extended Data Figure 8. Thymic development of $\mathrm{NAC1}^{-/-}$Tregs in the bone marrow chimeras. Bone marrow cells $\left(\mathrm{CD}^{-\mathrm{CD}} 8^{-}\right.$; Thy $\left.1.2^{+}\right)$from $\mathrm{WT}$ and $\mathrm{NACl}^{-/-}$mice were transferred into X-ray irradiated mice $\left(\right.$ Thy $\left.1.1^{+}\right)$. Six weeks later, the mice were euthanized, and the spleen, LNs and thymus were isolated to examine Treg development using flow cytometry. (A) $\mathrm{CD}^{+}{ }^{+}$oxP $3^{+}$cells. Data shown are the representatives of two identical experiments $(\mathrm{N}=10)$. (B) Thy $1.1^{+}$FoxP3 $3^{+}$cells. Data shown are the representatives of two identical experiments $(\mathrm{N}=10)$. (C) Total numbers of cells. Data shown are the mean \pm S.E.M. of a representative of two identical experiments $(\mathrm{N}=10) .{ }^{* *}, p<0.001$; ns, no statistical difference, Student's unpaired $t$-test $)$.

Extended Data Table 1. Detailed CpG analysis of mouse FoxP3 DNA methylation. Seven CpG sites of FoxP3 regulators were analyzed. 


\section{Extended Figure 1}

A

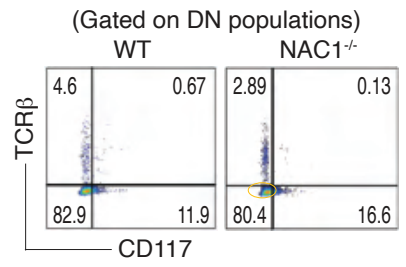

B

(Gated on DN4 populations)
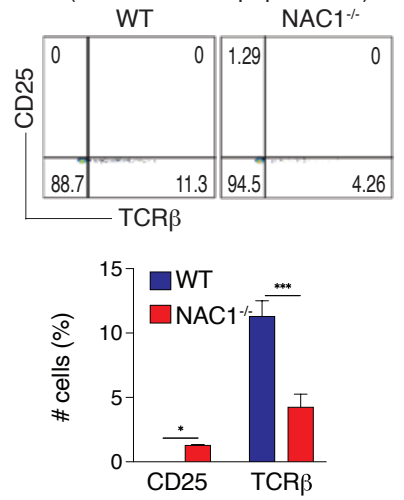


\section{Extended Figure 2}

A

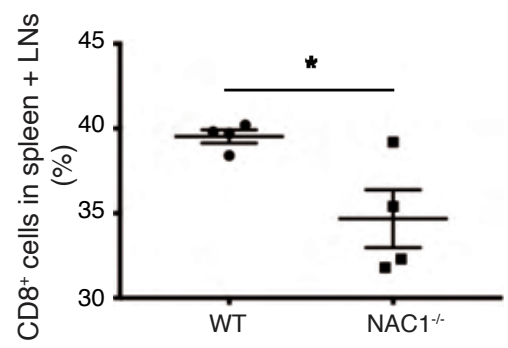

C

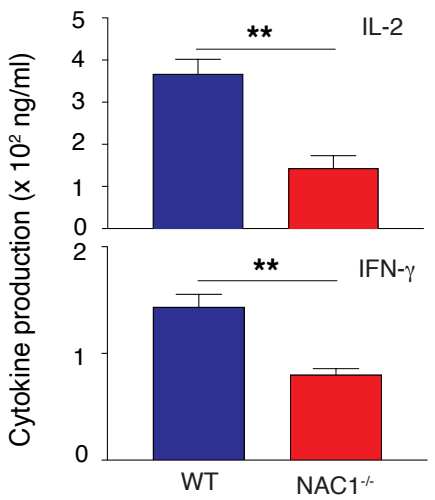

B

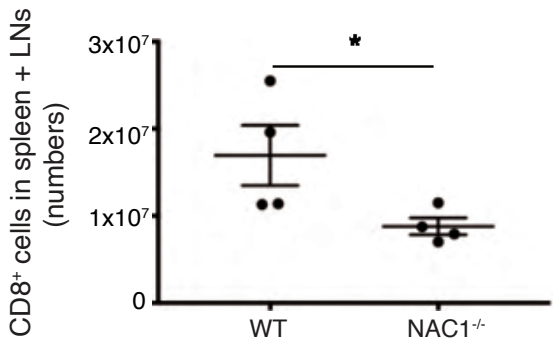

D

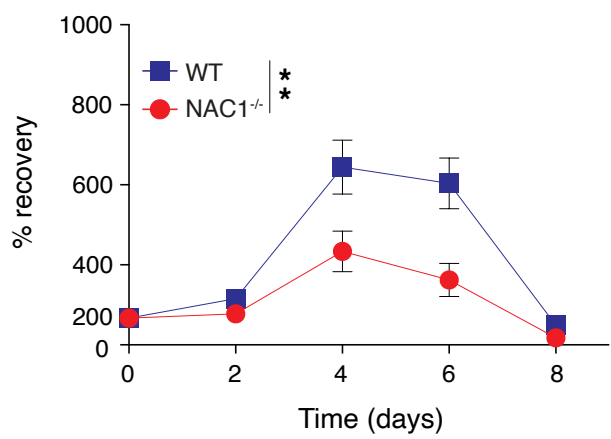




\section{Extended Figure 3}

A

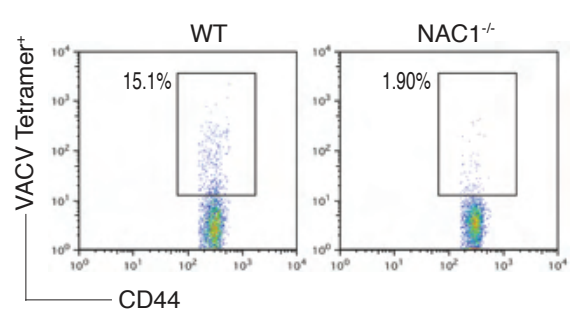

B

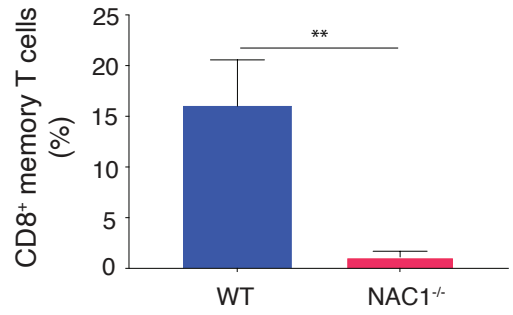




\section{Extended Figure 4}

A
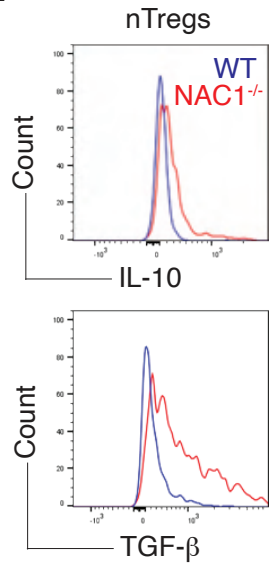

B
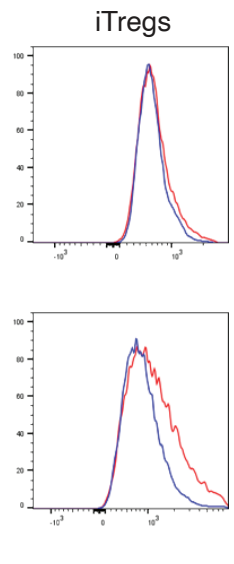
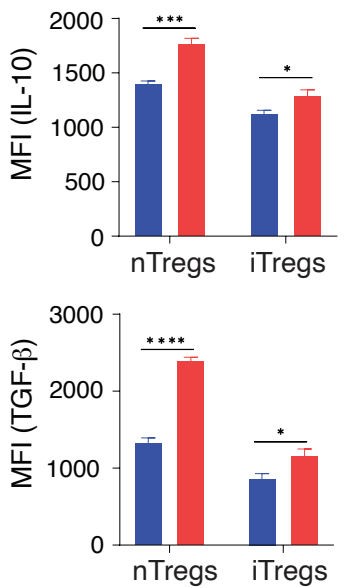


\section{Extended Figure 5}

A

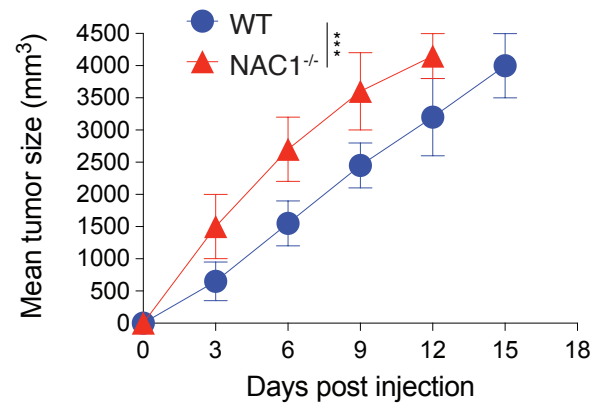

B

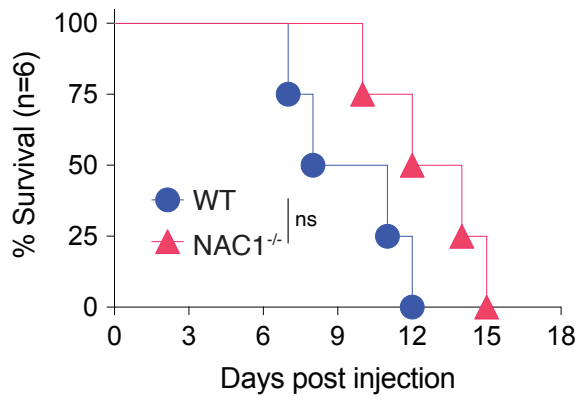




\section{Extended Figure 6}

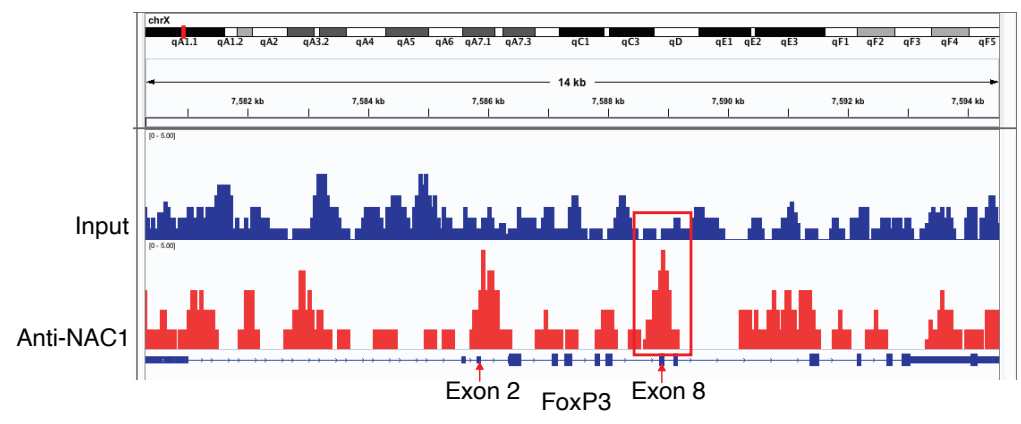




\section{Extended Figure 7}

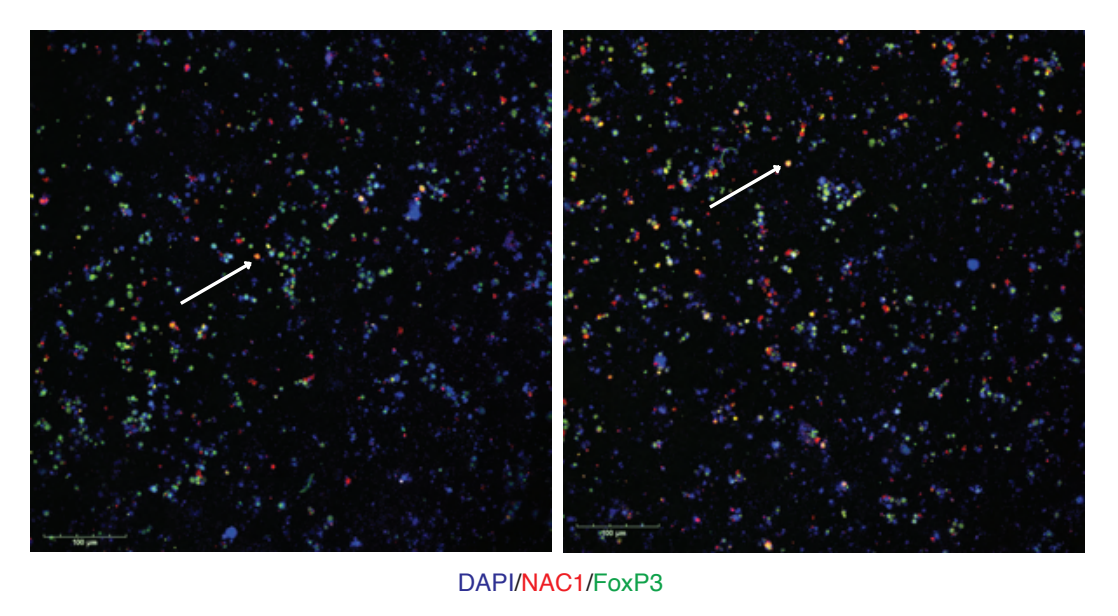

DAPI/NAC1/FoxP3
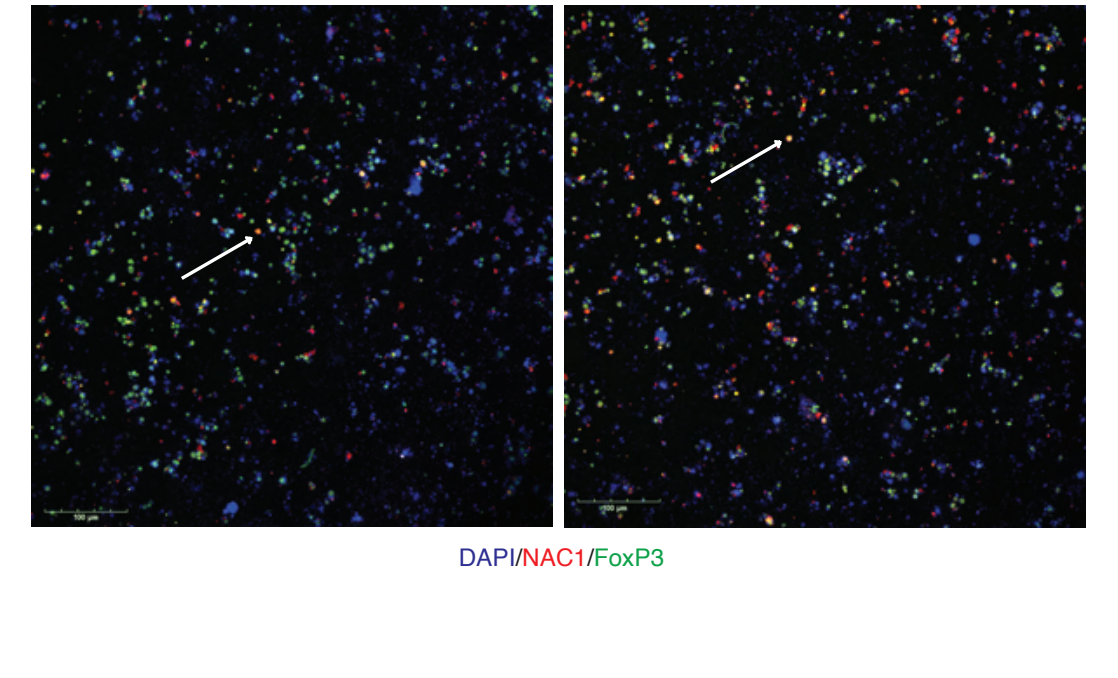

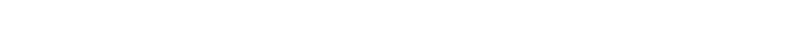
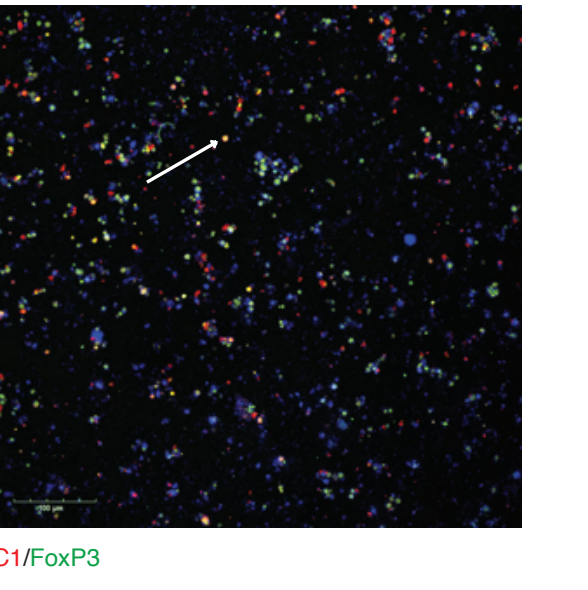


\section{Extended Figure 8}

A

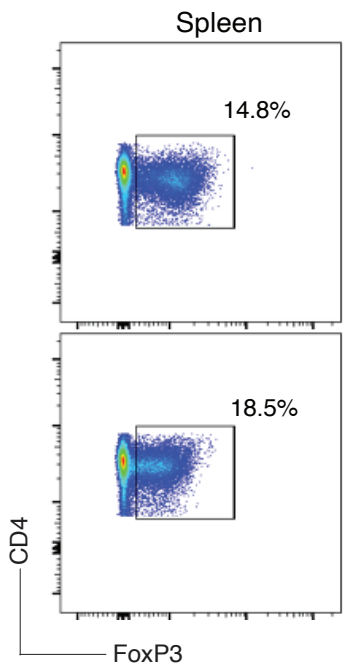

LNs

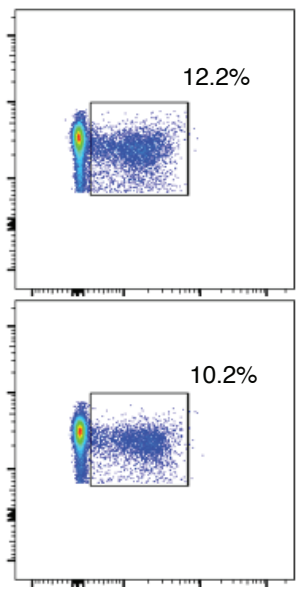

LNs

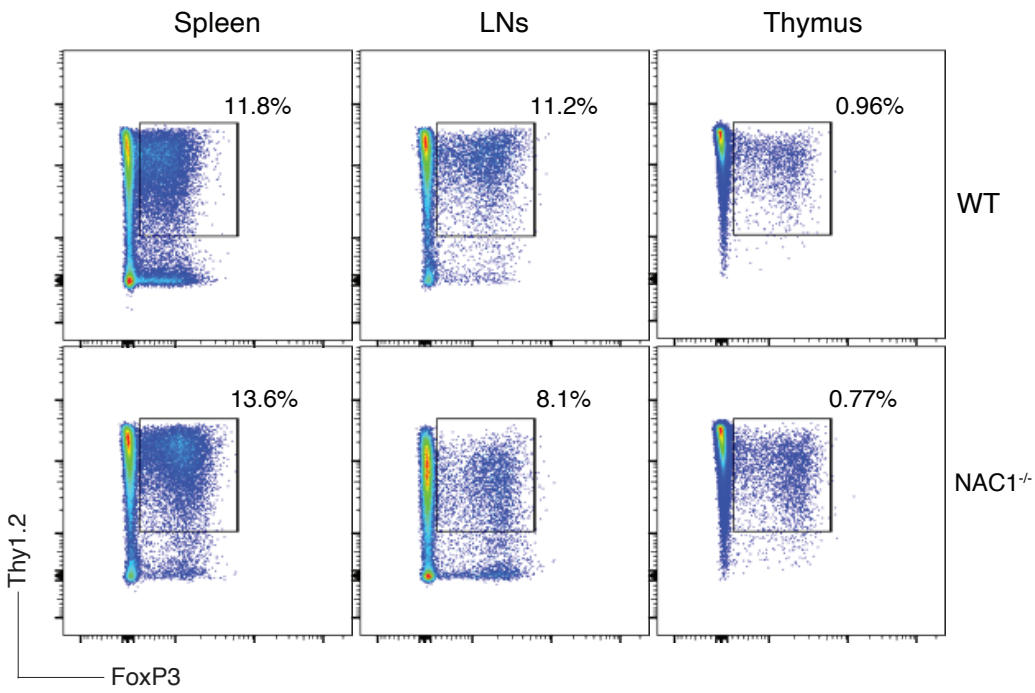

C

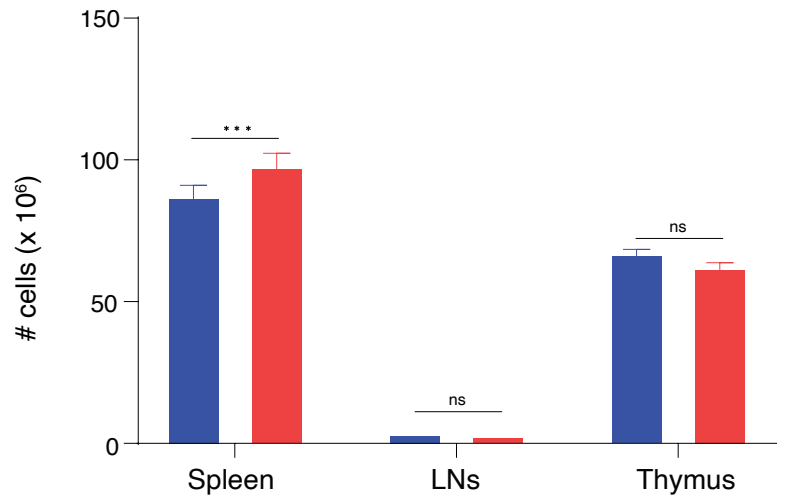




\section{Extended Table 1 Detailed CpG analysis of mouse FoxP3 DNA methylation}

\begin{tabular}{|c|c|c|c|c|c|c|}
\hline & \multicolumn{5}{|c|}{ Mouse FoxP3 DNA Methylation } \\
\hline Gene & Assay ID & Assay Location & From ATG & From TSS & Coordinates & \# of CpG \\
\hline Foxp3 & ADS657 & 5-Upstream & -12434 to -12224 & -5755 to -5545 & ChrX:7573921-7574131 & 25 \\
\hline Foxp3 & ADS1183 & 5-Upstream & -6750 to -6714 & -71 to -35 & ChrX: $7579605-7579641$ & 5 \\
\hline Foxp3 & ADS569 & 5-Upstream & -12210 to -12059 & -5531 to -5380 & ChrX: $7574145-7574296$ & 30 \\
\hline Foxp3 & ADS443 & Intron 1 & -2405 to -2353 & 4275 to 4327 & ChrX:7583950-7584002 & 3 \\
\hline Foxp3 & ADS442 & Intron 1 & -2555 to -2533 & 4125 to 4147 & ChrX: $7583800-7583822$ & 2 \\
\hline Foxp3 & ADS779 & Intron 1 & -2145 to -2075 & 4535 to 4605 & ChrX:7584210 -7584280 & 2 \\
\hline Foxp3 & ADS1184 & 3-Downstream & 23773 to 23905 & 30452 to 30584 & ChrX:7610127-7610259 & 10 \\
\hline
\end{tabular}

\begin{tabular}{|c|c|c|c|c|c|c|}
\hline Assay ID & Assay Location & From ATG & From Tss & $\mathrm{NCB137} / \mathrm{mm} 9$ & $\mathrm{GRCm} 38 / \mathrm{mm} 10$ & $\#$ of CpG \\
\hline ADS657-FS1 & Distal Promoter & -12434 to -12401 & -5755 to -5722 & Chrx:7151047-7151080 & ChrX:7573921-7573954 & 6 \\
\hline ADS657-FS2 & Distal Promoter & -12359 to -12353 & -5680 to -5674 & Chrx: $7151122-7151128$ & Chrx: $7573996-7574002$ & 2 \\
\hline ADS657-FS3 & Distal Promoter & -12335 to -12253 & -5656 to -5574 & Chrx: $7151146-7151228$ & ChrX: $7574020-7574102$ & 15 \\
\hline ADS657-FS4 & Distal Promoter & -12231 to -12225 & -5551 to -5545 & Chrix:7151251-7151257 & ChrX: $7574125-7574131$ & 2 \\
\hline ADS569-FS1 & Distal Promoter & -12210 to -12136 & -5531 to -5457 & Chrx:7151271-7151345 & ChrX: $7574145-7574219$ & 15 \\
\hline AD5569-F52 & Distal Promoter & -12118 to -12059 & -5439 to -5380 & Chrx: 7151363-7151422 & ChrX: $7574237-7574296$ & 15 \\
\hline ADS1183-FS & Proximal Promoter & -6750 to -6714 & -71 to -35 & Chrx: $7156731-7156767$ & ChrX: $7579605-7579641$ & 5 \\
\hline ADS442-FS & Intron 1 & -2555 to -2533 & +4125 to +4147 & ChrX:7160926-7160948 & ChrX: $7583800-7583822$ & 2 \\
\hline ADS443-FS & Intron 1 & -2405 to -2353 & +4275 to +4327 & Chrx: 7161076-7161128 & ChrX: $7583950-7584002$ & 3 \\
\hline ADS443-FS2 & Intron 1 & -2319 to -2287 & +4361 to +4393 & Chrx:7161162-7161194 & ChrX: $7584036-7584068$ & 3 \\
\hline ADSS68-FS1 & Intron 1 & -2369 to -2287 & +4311 to +4393 & Chrx:7161112-7161194 & Chrx: $7583986-7584068$ & 5 \\
\hline ADS568-FS2 & Intron 1 & -2238 to -2207 & +4442 to +4473 & Chrx: 7161243-7161274 & ChrX: $7584117-7584148$ & 4 \\
\hline ADS779-RS1 & Intron 1 & -2075 to -2145 & +4605 to +4535 & Chrx:7161406-7161336 & Chrx: $7584280-7584210$ & 2 \\
\hline ADS1184-FS1 & 3' downstream & +23773 to +23784 & +30452 to +30463 & Chrx: 7187253-7187264 & ChrX: $7610127-7610138$ & 2 \\
\hline ADS1184-FS2 & $3^{\prime}$ downstream & +23802 to +23840 & +30481 to +30519 & Chrx: $7187282-7187320$ & ChrX:7610156-7610194 & 5 \\
\hline ADS1184-FS3 & 3' downstream & +23863 to +23905 & +30542 to +30584 & Chrix:7187343-7187385 & Chrx:7610217-7610259 & 3 \\
\hline
\end{tabular}

